\title{
هدى اكتساب المفاهيم العلمية لدى طابة الصف الرابع الأساسي في الأردن باستخدام إستراتيجية التدريس المباشر وإستراتيجية التعلم القائم على النشاط
}

\author{
إعــــلداد \\ د. ما سامرة سعيد طحاينة \\ المملكة الأردنية الهاشمية
}

مجلة بحوث التربية النوعية - جامعة المنصورة

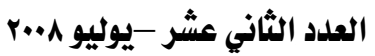


د . سامرةسعيد طحاينة

\section{مقدمهة}

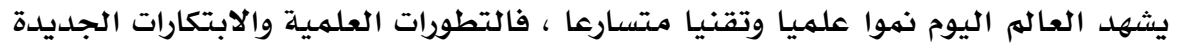

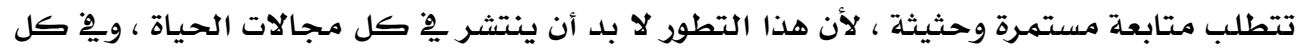

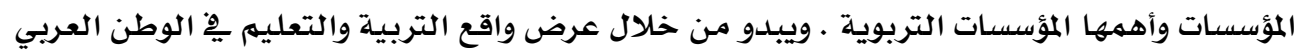

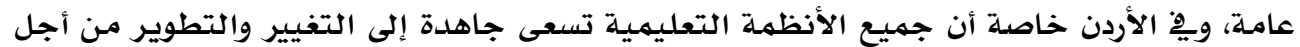

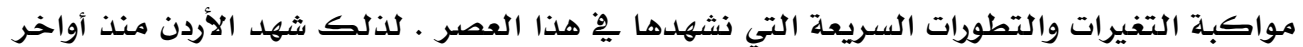

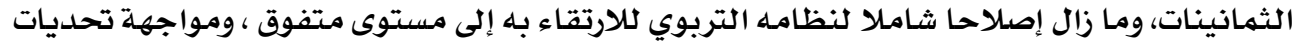

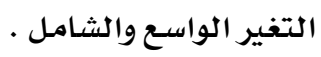

لقد طرحت حركة الإصلاح التربوي يِ الأردن عددا من الاتجاهات للنهوض بنوعية التربية

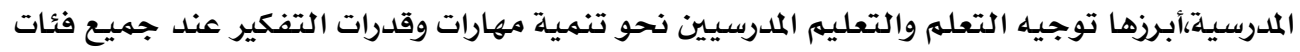

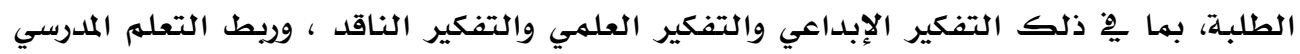

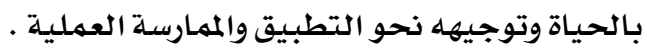

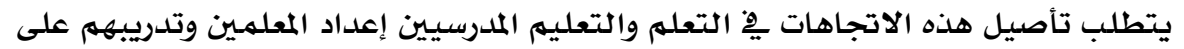

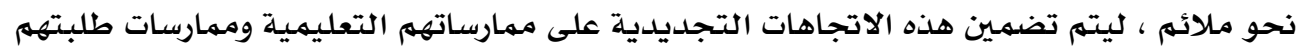

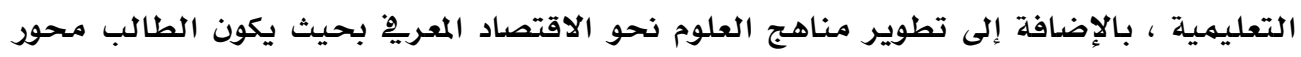

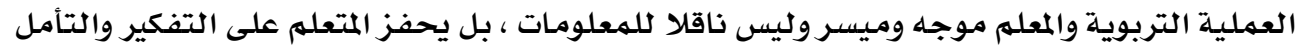

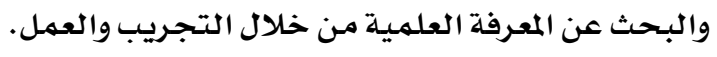

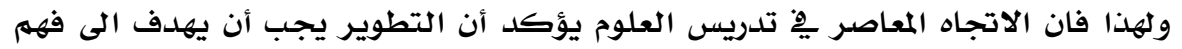

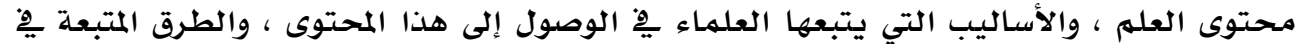
تدريسه، ( عطالله ب... ( ) ).

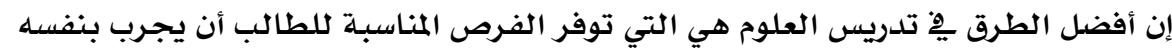

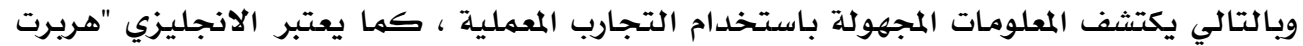

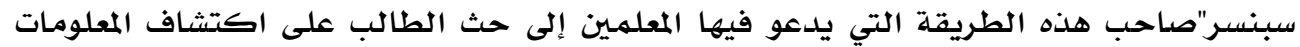

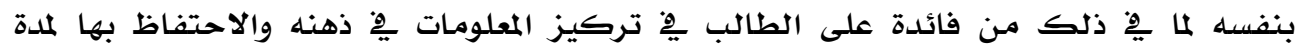

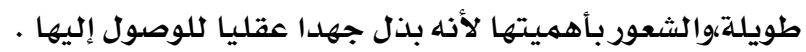




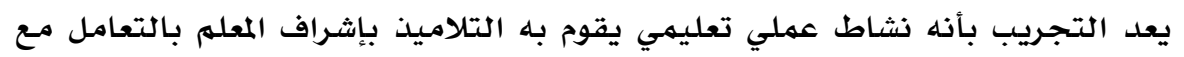

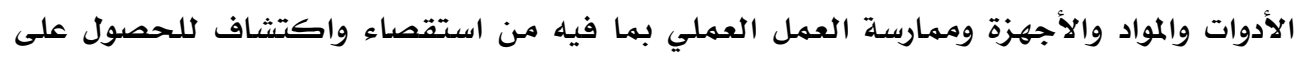

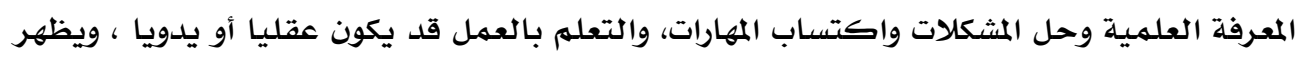

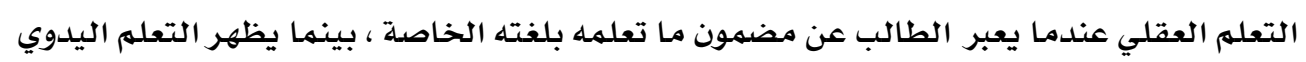

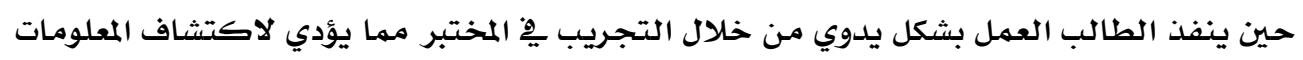

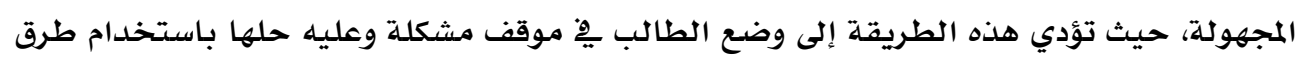

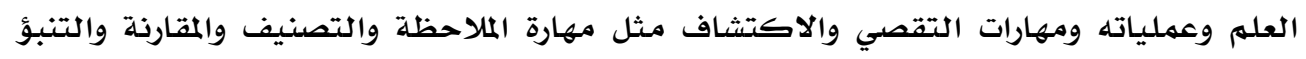
والقياس والتقدير والتحليل والتركيب وغيرها ، و (الخليلي وآخرون , 1997).

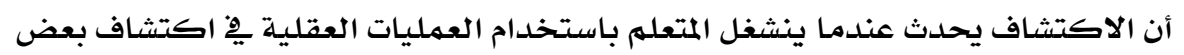

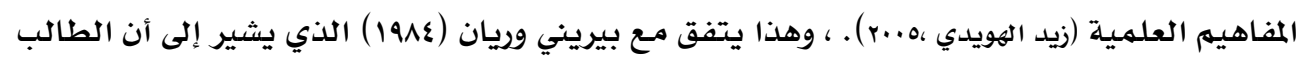

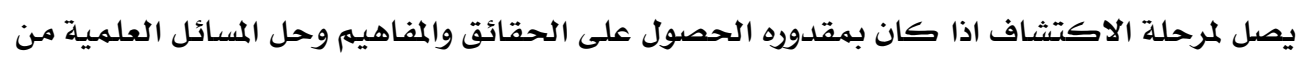
خلال العمل بالأنشطة. إن العمل من خلال النشاط يؤدي الى الاكتشاف ويعني الوصول لشيء موجود من قبل لكنه

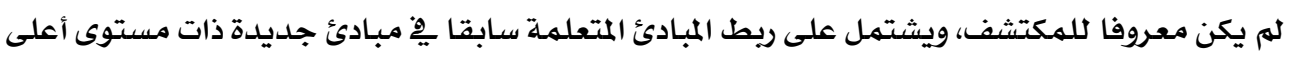

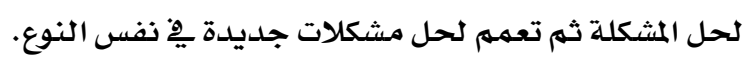

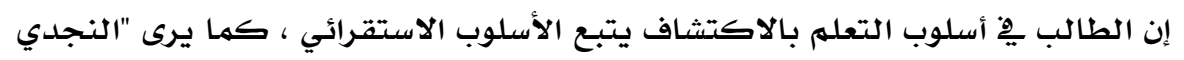

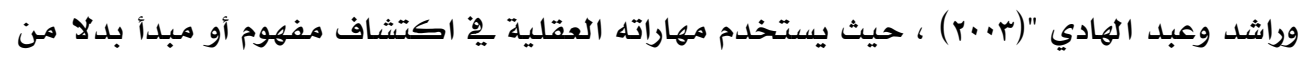

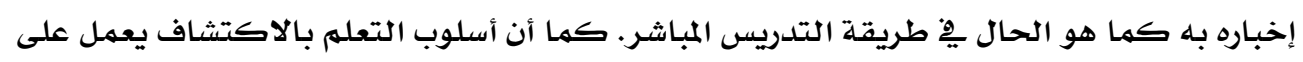

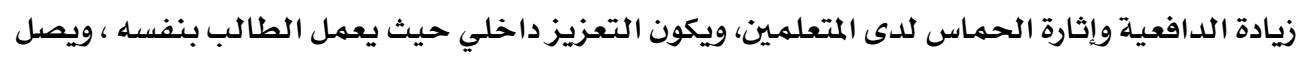

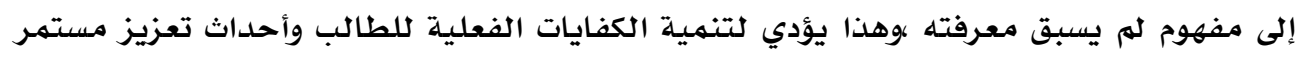

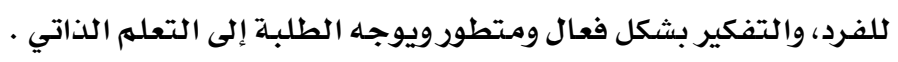

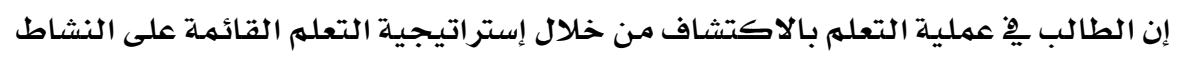

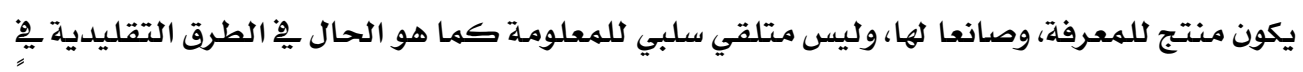

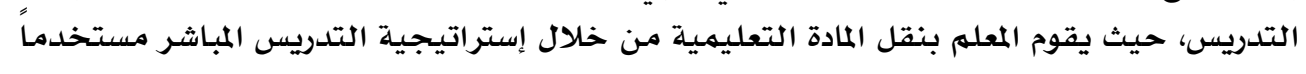

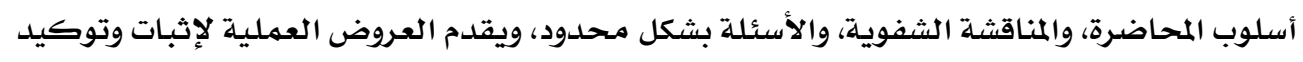

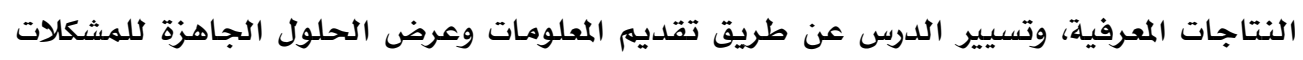

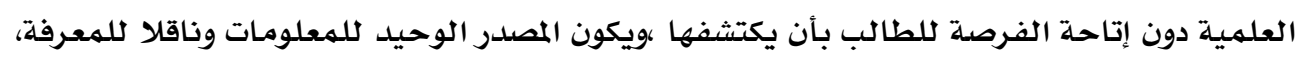
وهنا لا يكون للطالب دور يِّ التوصل للمعرفة الطواجة العلمية إنما متلقي سلبي لها. إن معظم الحقائق والمفاهيم والنظريات يِ العلوم يمكن التثبت من صحتها بواسطة

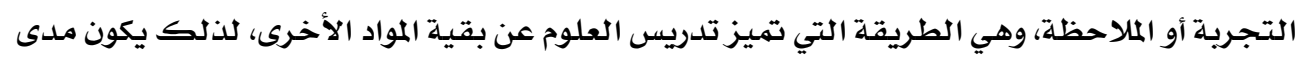
اكتساب المفاهيم العلمية أكبر وبصورة وظيفية الملاحفية ( الهويدي ه...r). 


\section{هشكلة الدراسة :}

تتمحور مشكلة الدراسة بوجود الحاجة لتحسين طرائق التدريس التي تؤدي إلى الفهم

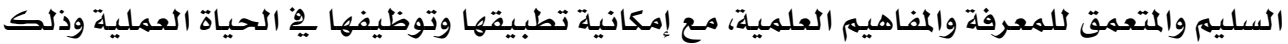

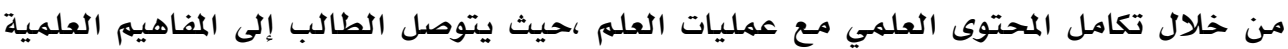

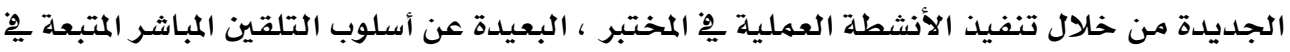

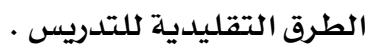
أسئلة الدراسة : التقليدة :

* * هل يختلف أداء الطالبات على الاختبار التحصيلي باختلاف طريقة التدريس ؟

\section{أهميية الدراسة : تهل:}

تستمد الدراسلة أهميتها من مجالين وهما :

\section{الأهمية النظرية للدراسة :}

تعود إلى أهمية توظيف إستراتيجية التعلهم القائم على النشاط العلمي ، حيث يمارس

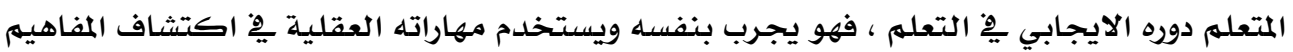

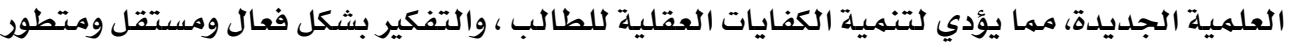

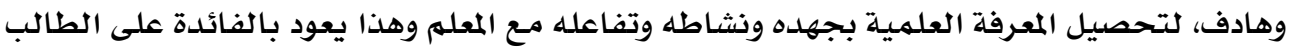

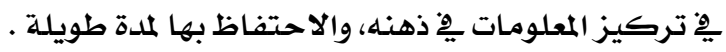

\section{الأهمية التطبيقية للدراسة :}

تعود إلى أهمية إتباع الاستراتيجيات الحديثة يِّ تدريس العلوم، والتي تركز على الدئ الدور

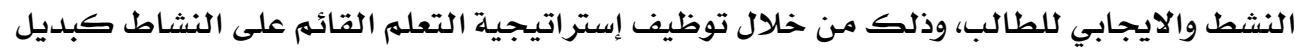

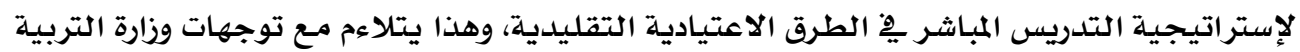

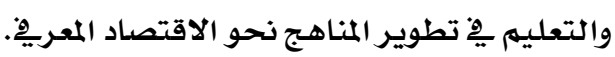

التعريفات الإجرائية :-

\section{إستراتيجية التدريس المباشر :}

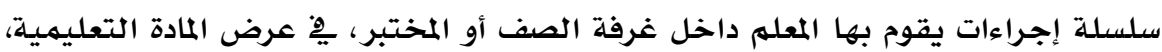

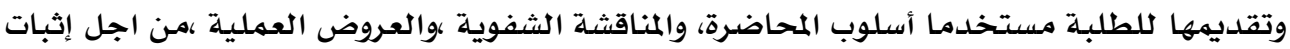

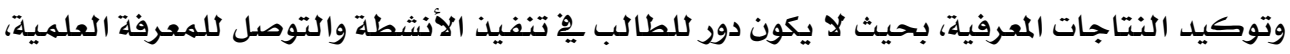

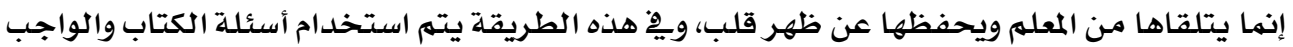

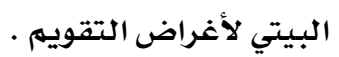


طريقة تدريس تعتمد على تنفيذ الدرس من خلال ممارسة الأنشطة والتجارب العملية من

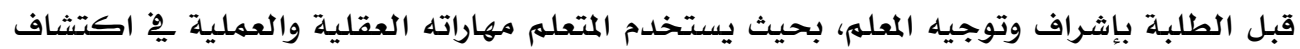

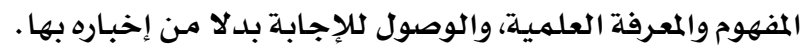

\section{المفهوم العلمي : المحمد}

مجموعة من الحقائق والأفكار المجردة المنظمة التي ترتبط بعلاقات محددة ويعبر عنها

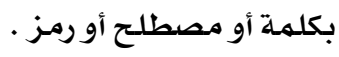

\section{حدود الدراسة وهمدداتها :}

- اقتصرت الدراسة على طالبات الصف الرابع الأساسي فِّ مدرسة خولة بنت الأزور

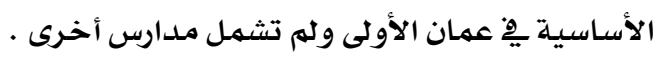

- اقتصرت الدراسة على الإناث دون الذكور

\section{الدراسات السابقة :-}

يشير (زيتون \&..r ) إلى أن الأنشطة العلمية تعد ركنا أساسيا يِّ تدريس العلوم، ويعرف

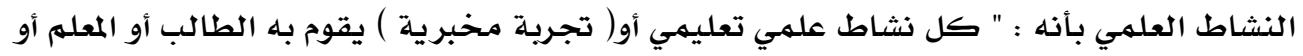

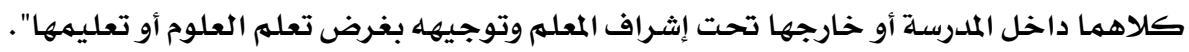

من مميزات النشاطات العلمية المفتوحة النهاية أن يرتبط النشاط العلمي أو التجرية

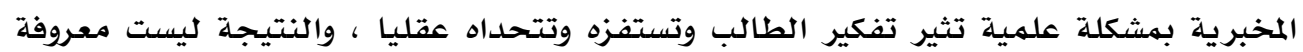

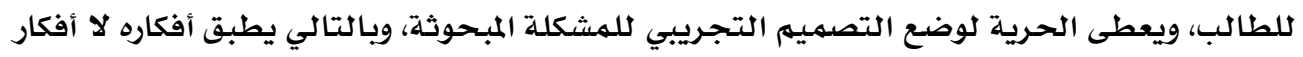

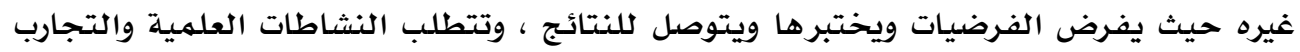

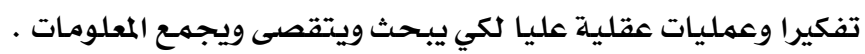

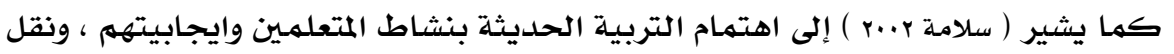

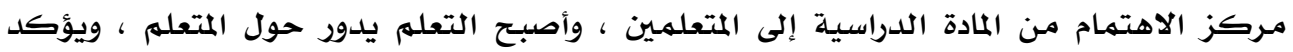

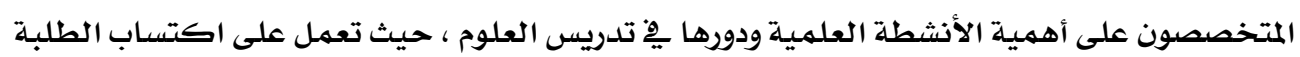

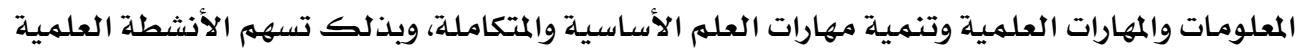

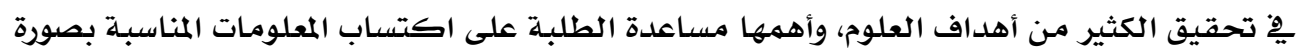

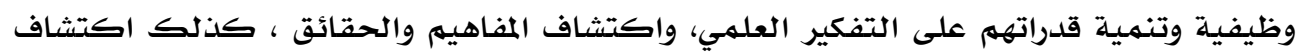

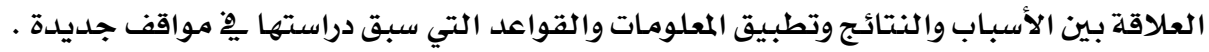
أما (الخليلي وآخرون , ب991) يعرف التجريب بأنه نشاط عملي تعليمي يقوم به الطلاب بإبـراف

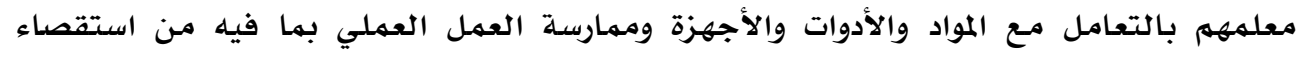

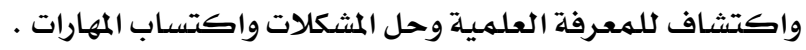


ويشير ( الهويدي ه..r ) إلى أن اكتشاف المعلومات المجهولة يحدث من خلال التجريب عندما

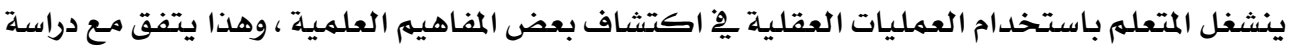

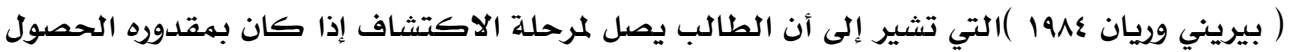

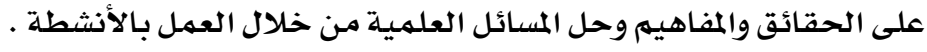
ويؤكد (مراد ra91 ) أنه لا يهكن أن نتصور استخدام برنامـج فعال لتدريس العلوم يخلو من

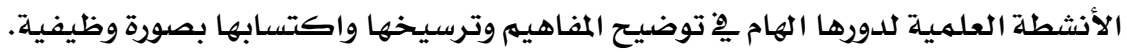
أما (فريدمان 199v) فقد استقصى أثر استخدام برنامج أنشطة الخبرة المباشرة هِِ الفيزياء

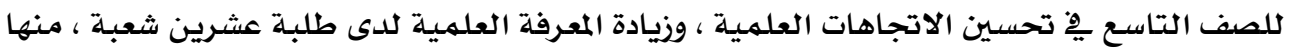

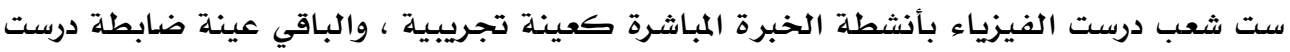

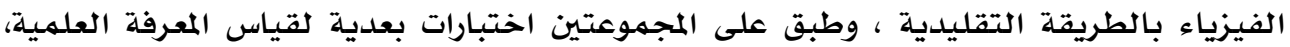

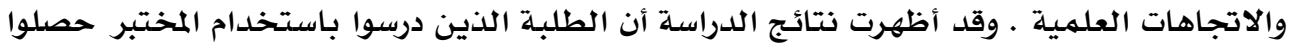

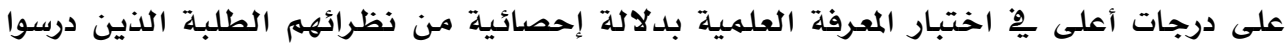

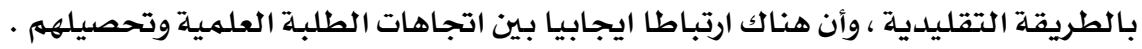

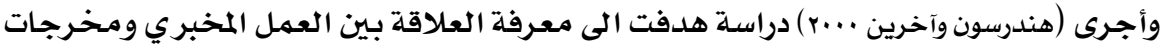

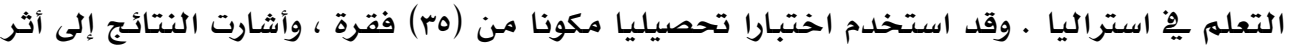

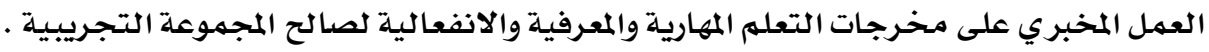

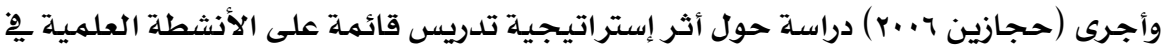

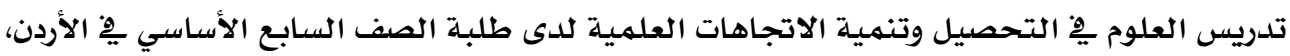

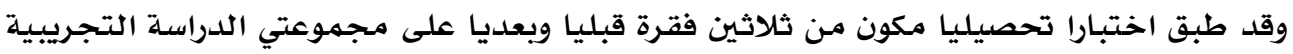

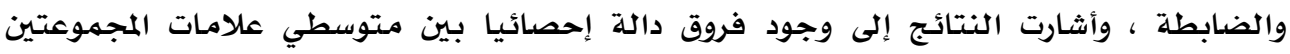

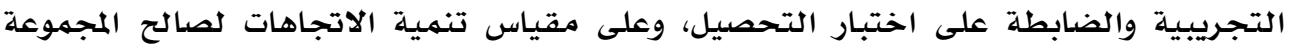

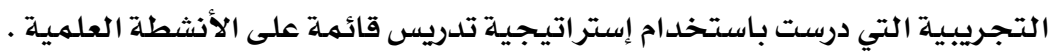

\section{تختلف الدراسة الحالية عن الدراسات السابقة بما يلي :}

لقد بحثت بعض الدراسـات السابقة أثر الأنشطة العلمية يِّ تدريس العلوم ِِّ متغيرات مثل

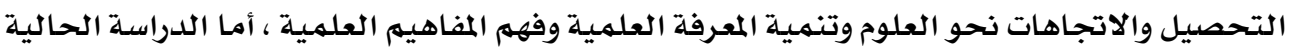

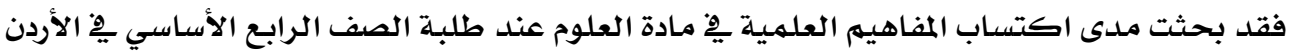

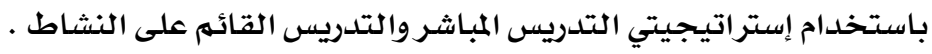

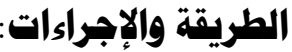

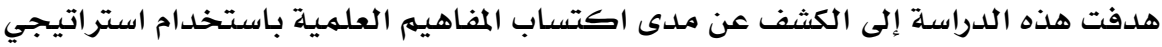

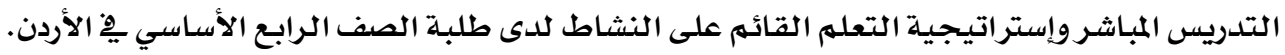




\section{مجتمـع الدراسةة:}

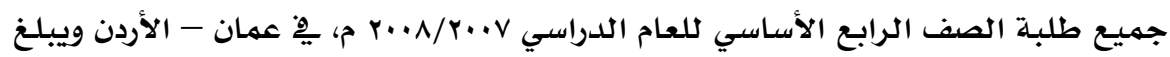

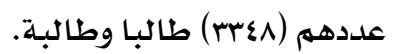

\section{أفراد الدراسـة:}

بلغت عينة الدراسة ( V7 ) طالبة من مدرسة خولة بنت الأزور الأساسية /عمان الأولى (بلى

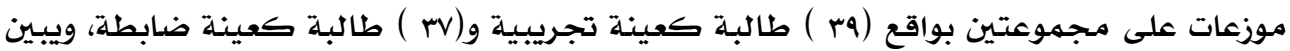

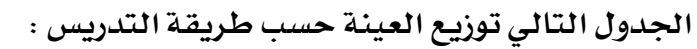

\begin{tabular}{|c|c|c|c|}
\hline المجمهوع & العينة التجريبية & العينة الضابطة & خولة بنت الأزور الأسـاسية \\
\hline vi & rq & rv & عدد الطالبـات \\
\hline
\end{tabular}

\section{أدوات الدراسة :}

(1)

تم الإعداد للاختبار من خلال إتباع الخطوات التالية :

أ- تم الطلب من معلمة العلوم للصف الرابع الأساسي يِّ مدرسة خولة بنت الأزور الأساسية

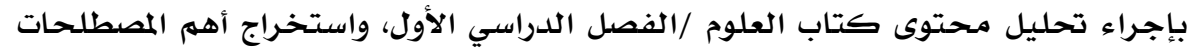

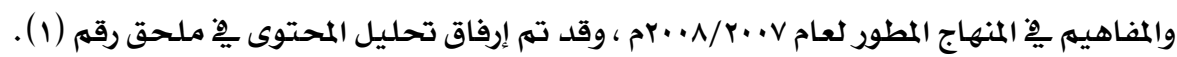

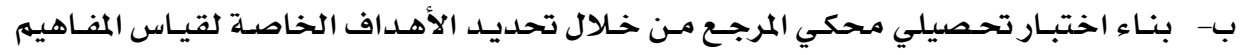

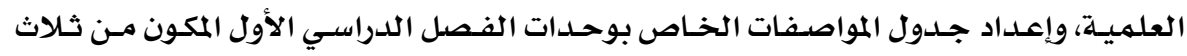

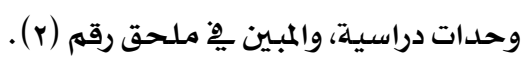

ج- تم كتابة فقرات الاختبار وفق جلدول المواصفات لقياس المصطلحات والمفاهيم على كل

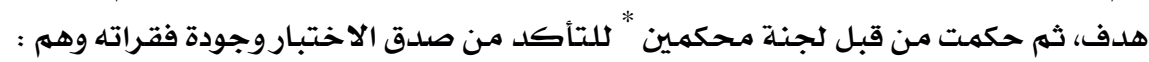

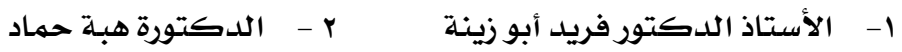

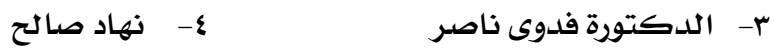

د- إخراج الاختبار بصورته النهائية بعد التحقق من صدق المحكمين وصدق المحتوى من خلال

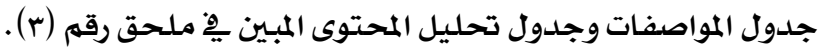

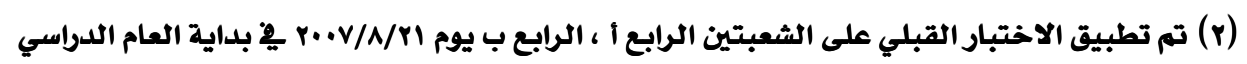

قبل البدء بتدريس المنهاج بالطريقتين، وذلك للتحقي الوحق من تكافؤ الشعبتين.

* الأستاذ الدكتور/ فريد أبو زينة ، الدكتورة/ هبة حماد ، الدكتورة فدوى ناصر ، نهاد صالح 


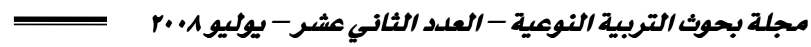

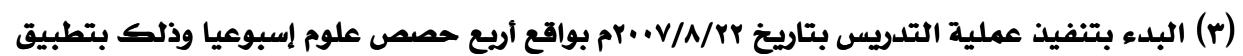

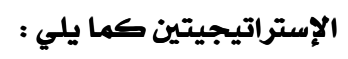

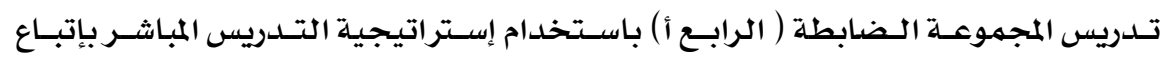

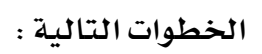

* شرح المادة من قبل المعلمهة بشكل رئيسي باستخدام أسلوب المحاضرة والمناقشة الشفوية

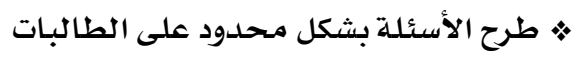

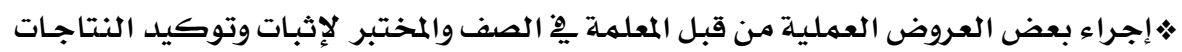

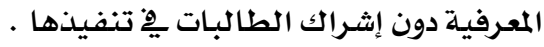

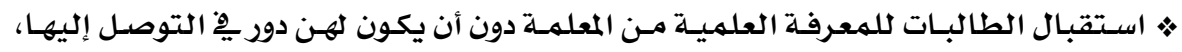
وحفظ المادة المقدمة واستظهارها كمها هي.

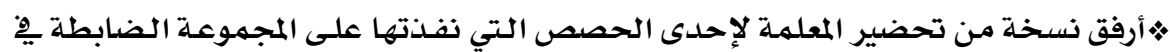

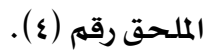

(ب)- تدريس المجموعة التجريبية ( الرابع ب) باستخدام إستراتيجية التعلهم القائم على النشاط

$$
\text { بإتباع الخطوات التالية : تلدريس المجهوعة التجريبة }
$$

$$
\text { • * تقسيم الطالبات إلى مجموعات متكافئة. }
$$

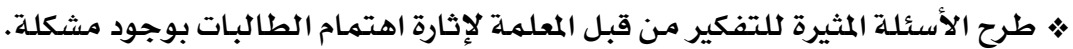

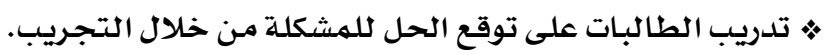

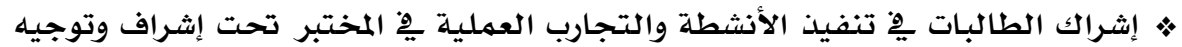
المعلمة. • مشاركة الطالبات يِّ استنتاج المعرفة العلمية بإتباع الأسلوب الاستقرائي يٌْ اكتشاف

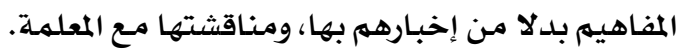

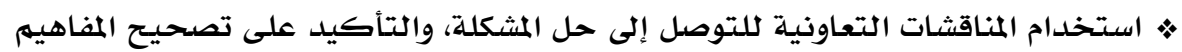

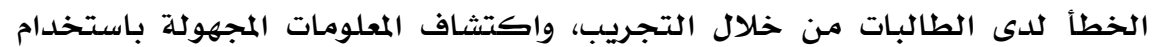

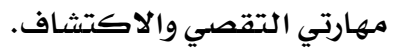

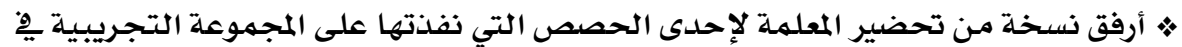

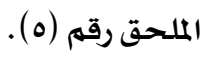

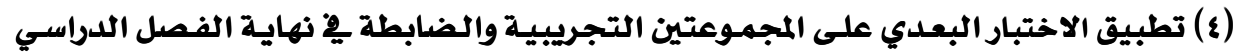

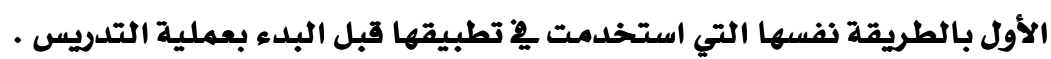

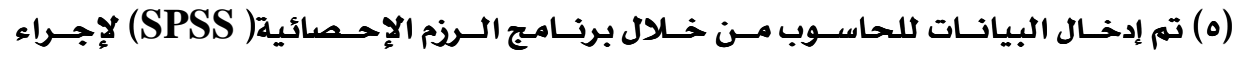


- للتأكد من تكافؤ مجموعتي الدراسة التجريبية والضابطة تم تطبيق اختبار التحصيل

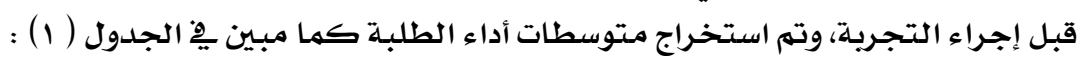

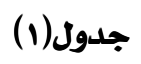

متوسط أداء المجموعتين التجريبية والضابطة على اختبار مدى اكتساب المفاهيم العلمية التحصيلي القبلي

\begin{tabular}{|c|c|c|c|c|c|}
\hline & المجموعة & العدد & المتوسط & الانحراف المعياري & الخطأ \\
\hline test 1 & الضابطة & 37 & 11.86 & 2.551 & .419 \\
\hline & التجريبية & 39 & 11.92 & 2.264 & .363 \\
\hline
\end{tabular}

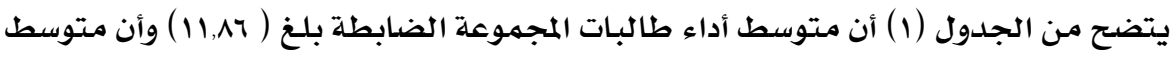

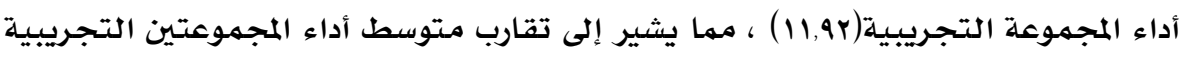
والضابطة .

بعد تطبيق إجراءات البحث كاملة تم إجراء الاختبار البعدي حيث تم إعادة تطبيق الاختبار

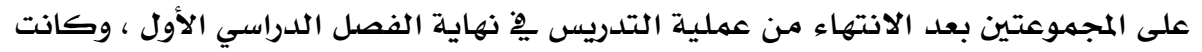

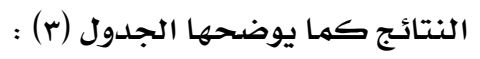

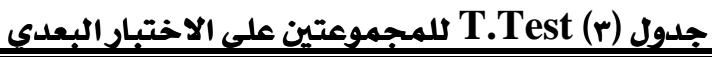

\begin{tabular}{|c|c|c|c|c|c|}
\hline & المجموعة & العددد & المتوسط & الانحراف المعياري & متوسط الخطأ \\
\hline \multirow[t]{2}{*}{ test2 } & ضابطة & 37 & 60.32 & 21.943 & 3.607 \\
\hline & تجريبية & 39 & 76.33 & 13.819 & 2.213 \\
\hline
\end{tabular}

- ميلاحظ من الجدول (r) أن متوسط أداء المجموعة الضابطة ( rr, •r)، بينما بلغ متوسط أداء

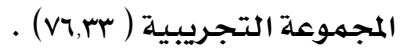

- لفحص الفروق بين متوسط أداء المجموعتين تم اجراء (T. test) على الاختبار البعدي

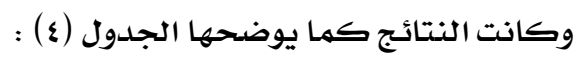

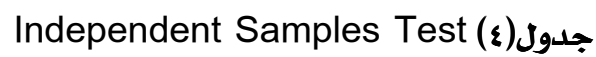

\begin{tabular}{|c|c|c|c|c|c|c|c|}
\hline & & \multicolumn{2}{|c|}{$\begin{array}{c}\text { Levene's Test for } \\
\text { Equalityof Variances }\end{array}$} & \multicolumn{4}{|c|}{ t-test for Equality of Means } \\
\hline & & 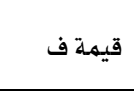 & مستوى & $t$ & الحرية & مستوى الدلالة & متوسط الفروق \\
\hline \multirow[t]{2}{*}{ الاختبار } & $\begin{array}{c}\text { Equal variances } \\
\text { assumed }\end{array}$ & 8.619 & .004 & -3.827 & 74 & .000 & -16.009 \\
\hline & $\begin{array}{c}\text { Equal variances } \\
\text { not assumed }\end{array}$ & & & -3.783 & 60.124 & .000 & -16.009 \\
\hline
\end{tabular}


مجلة بحوث التربية النوعية - العلد الثاني عشر - يوليو1.•r

يلاحظ من الجدول ( ع) أن الفروق ين متوسط أداء المجموعة التجريبية والمجموعة الضـابطة

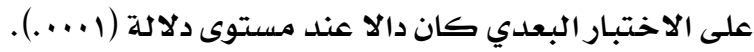

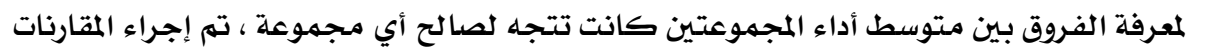

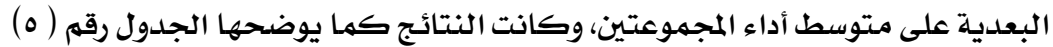
حيث كانت الفروق لصالح المجموعة التجريبية .

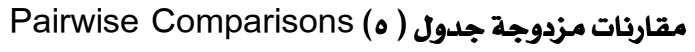

Dependent Variable: test 2

\begin{tabular}{|c|c|c|c|c|}
\hline (l) type & (J) type & متوسط الفروق( & Std. Error & مستوى الدلالة \\
\hline الضابطة & التجريبية & $-16.009(*)$ & 4.184 & .000 \\
\hline التجريبية & الضابطة & 16.009 (*) & 4.184 & .000 \\
\hline
\end{tabular}

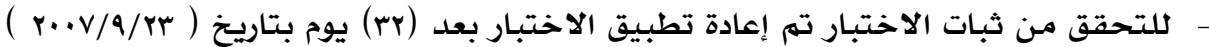

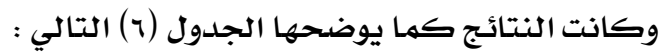

جدول(7) - معامل ثبات الاختبار

\begin{tabular}{|c|c|c|c|}
\hline & & التطبيق الأول & التطبيق الثاني \\
\hline \multirow{3}{*}{ التطبيق الأول } & Pearson Correlation & 1 & $.981(* *)$ \\
\hline & Sig. (2-tailed) & & .000 \\
\hline & $\mathrm{N}$ & 76 & 76 \\
\hline \multirow[t]{3}{*}{ التطبيق الثاني } & Pearson Correlation & $.981(* *)$ & 1 \\
\hline & Sig. (2-tailed) & .000 & \\
\hline & $\mathrm{N}$ & 76 & 76 \\
\hline
\end{tabular}

* Correlation is significant at the 0.01 level (2-tailed).

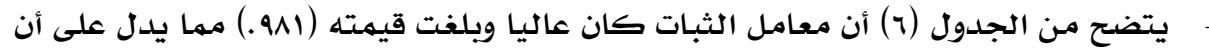

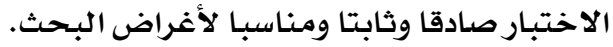

يلاحظ من عرض النتائج السابقة أن :

*عند إجراء الامتحان القبلي كان متوسط أداء المجموعتين التجريبية والضابطة منخفضا ومتقاريا على اختبار التحصيل الخاص بمدى الكتساب المفاهيم العلمية ، مما يعني تكافؤ

$$
\text { مجموعتي الدراسـة. }
$$

• عند استخراج متوسطات أداء الطالبات المتوافرة والتي اشتملت على بيانات عن اختبار

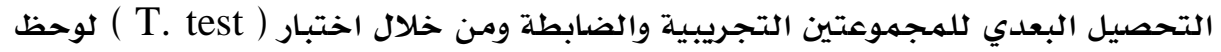

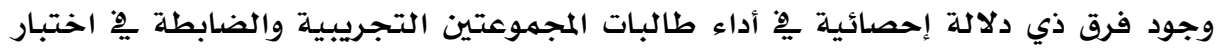


التحصيل البعدي تعود لطريقة التدريس .كما تبين أن الفروق الإحصائية كانت ذات دلالة

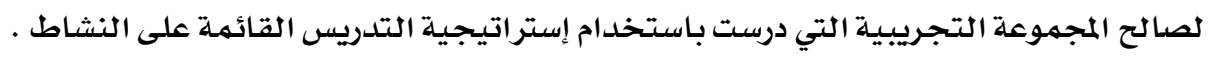

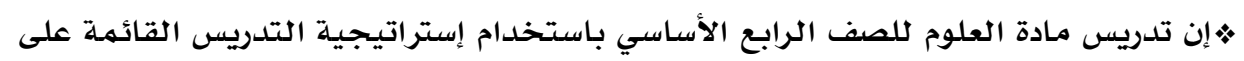

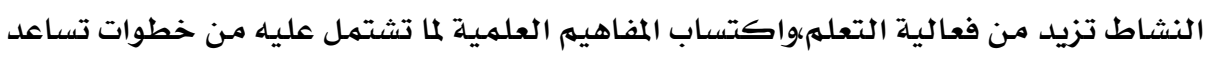

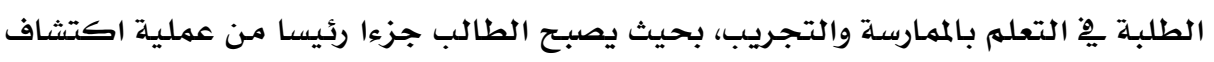

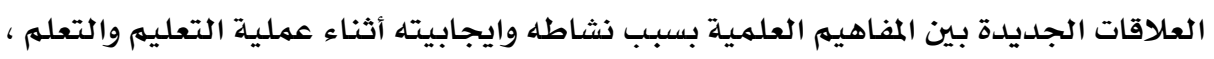

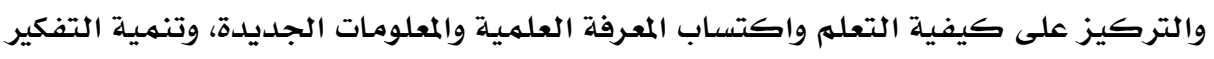

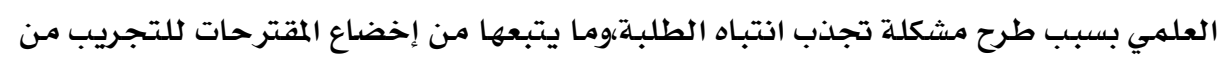

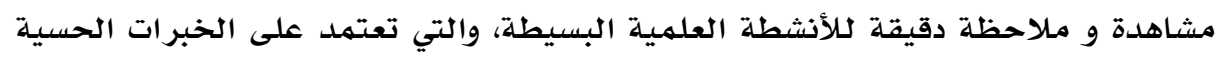

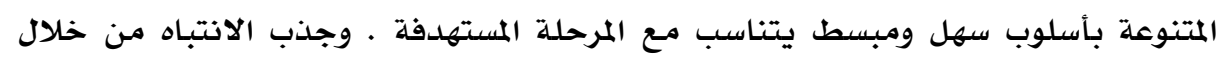

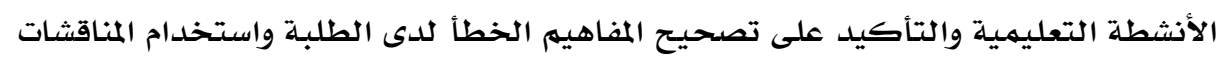

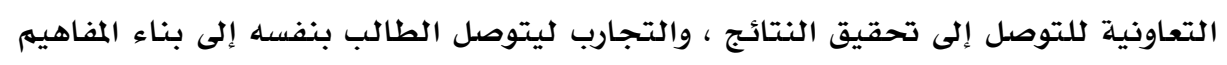

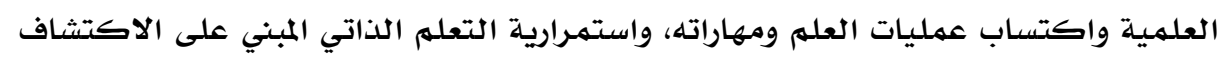

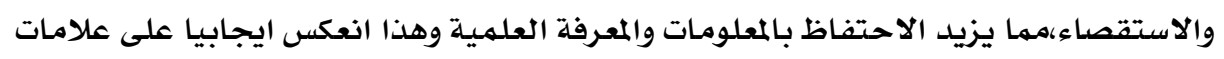

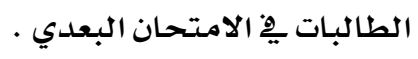

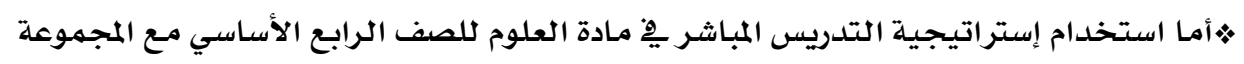

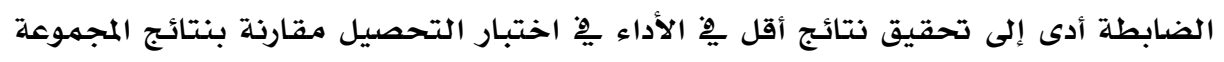

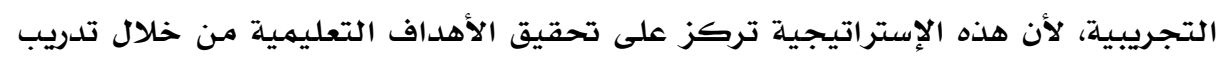

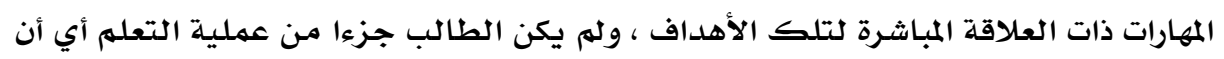

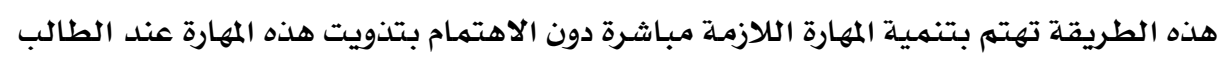

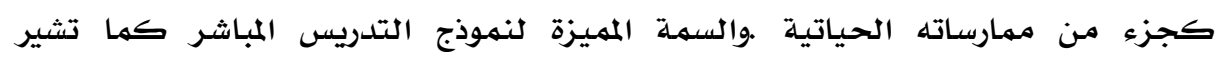

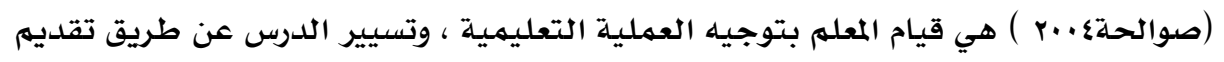

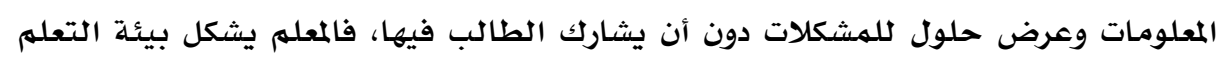

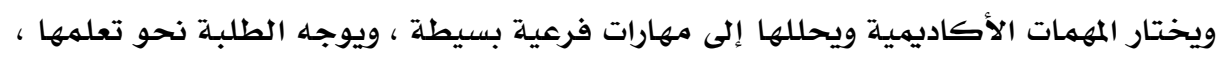

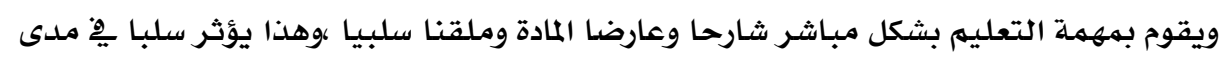
اكتساب المفاهيهم بصورة وظيفية التعليم بشكل مباثر ثارية

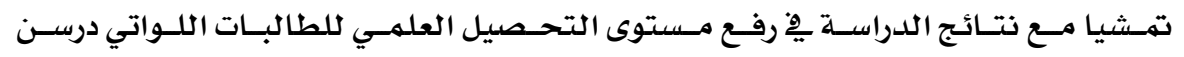

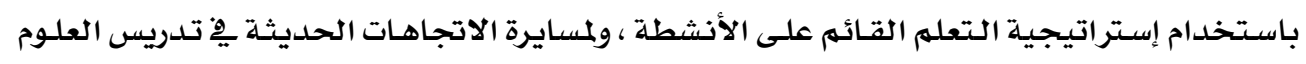
توصي الدراسـة بما يلي :

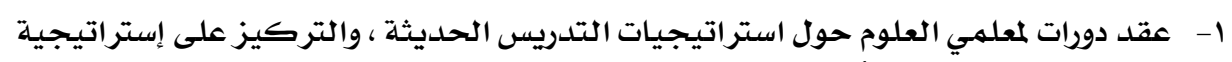

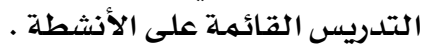




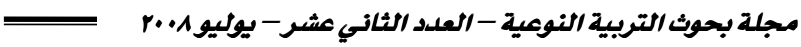

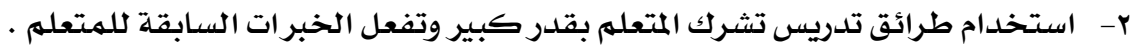
ץ- تعديل شكل الأنشطة العلميـة تتشهل على نهايات مفتوحة تشجع على التجريب

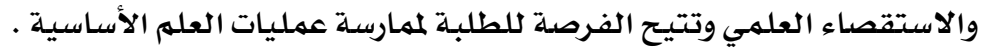

ع- إجراء دراسـات للكشف عن فاعلية إستراتيجية التدريس القائمهة على الأنشطة العلميـة فِ

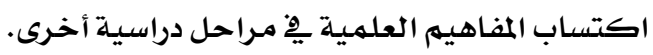

: المراجع

المراجع العربية: المرابة

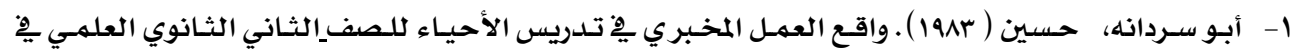
المدارس الحكومية. رسالة ماجستير غير منشورة، الجامعة الأردنية، عمان،الأردن. ץ- البغدادي ، محمـد. (199V) الأنشطة مفتوحـة النهايـة لاكتسـاب تلميـذ المدرسـة الابتدائيـة المفهوم العلهـي

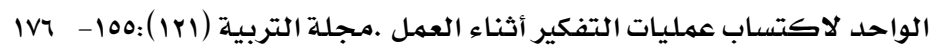

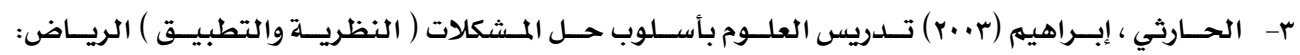
مكتبة الشقري.

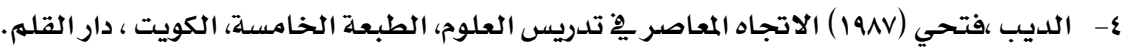

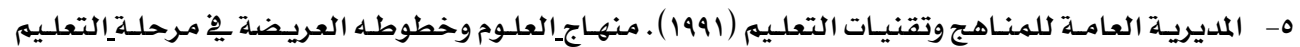
الأساسي. عمان، وزارة التربية والتعليه.

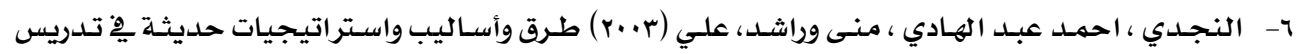
العلوم، الطبعة الأولى ، القاهرة ،: دار الفكر العربي.

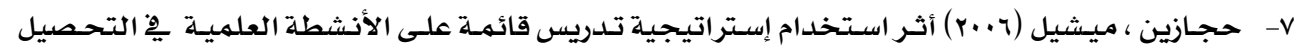
وتنمية الاتجاهات العلمية لدى طلبـة المرحلة الأسـاسية ِِِ الأردن، رسالة دكتوراه غير منشورة ، عمان .

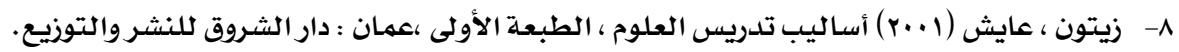

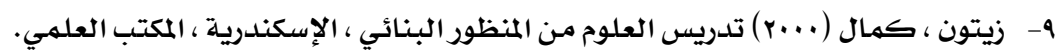

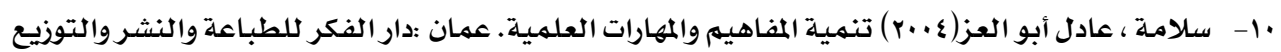

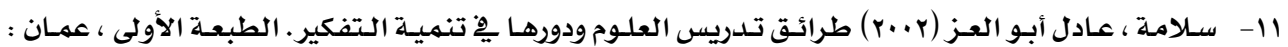
دار الفكر للطباعة والنشر .

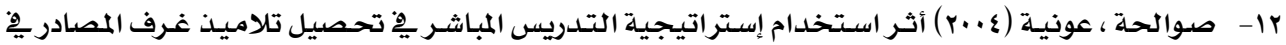
الرياضيات وتنميلة الاتجاهات ومفهوم الذات الأكاديهي لديهم ، رسالة دكتوراه غير منشورة ، عمان .

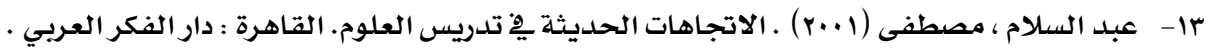

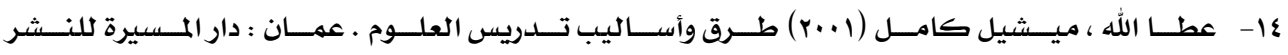
والتوزيع والطباعة .

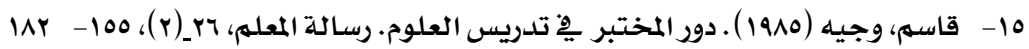

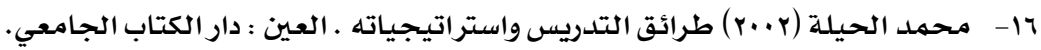




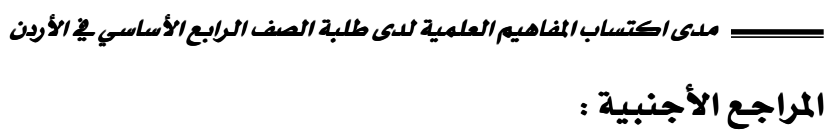

1-Al- Bashaireh, Z. A. (1998). A study of the new Science Curriculum in Jordan secondary schools with special reference to Science. Unpublished Doctoral Dissertation. University of Sheffield, England .

2- Blosser, p .(1983). The role of the laboratory in science teaching. School Science and Mathematics. 83 (2), 165- 169.

3-Freedman, M.P. (1997). Relation among laboratory instruction, attitudes toward science, and achievement in Science knowledge. Journal of Research in Science Teaching.34 (4), 343-357.

4-Hant,C, Mulhall, P, Berry, Loughran, J, and Gunstone R(2000) What is the purpose from doing experiment, Journal Of Research In Science Education37(7):655

5- Henderson, D. Fesher, D. \&Fraser, B.(2000)Interpersonal Behavior Laboratory Learning Environment And Students Outcomes In Senior Classes. Journal OfResearch in Science Teaching,20(8):33-40

6- Shrigly, R. (1983). The attitude concept and science teaching. Science Education. 67(4), 425- 442. 
هدفت هذه الدراسة إلى الكثف عن مدلى اكتساب المفاهيم العلمية يِّ مادة العلوم العامـة

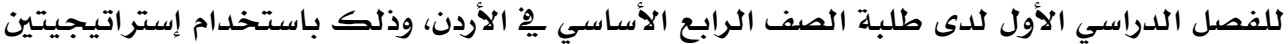

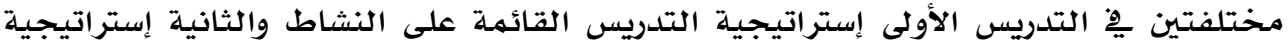

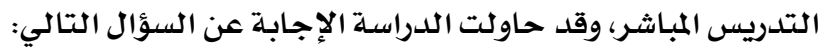

ا- هل يختلف أداء الطالبات على الاختبار التحصيلي باختلاف طريقة التدريس؟

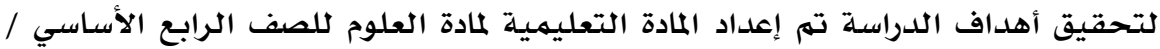
الفصل الأول بأسلوب إستراتيجية تدريس قائمة على الأنثطة العلمية ، وإستر اتيجية التدريس المباشر

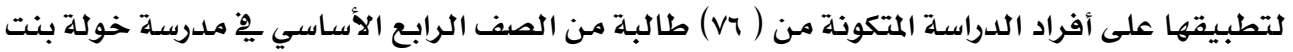

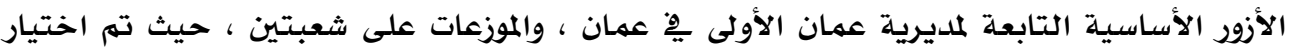

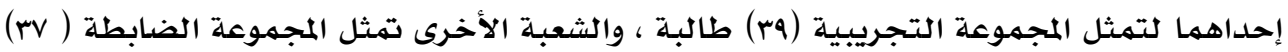
طالبة أيضا.

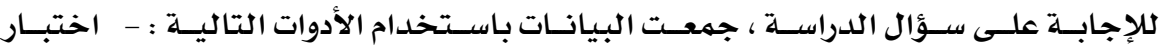

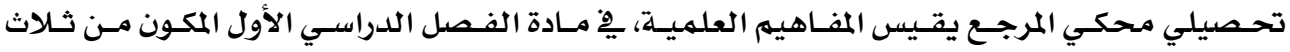
وحدات وهي :

الكائنات الحية والبيئة - الضوء - خصائص المادة وأثكا لها تكون الاختبار من ثمانية أسئلة

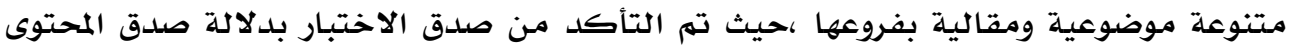

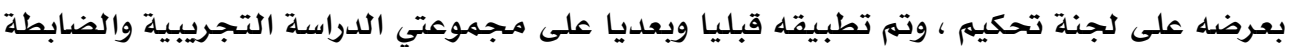

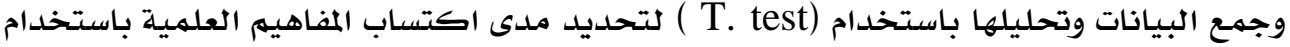

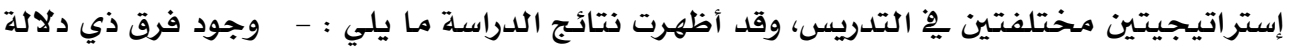

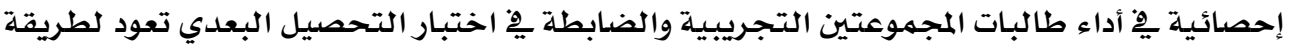
التدريس .

أن الفروق الإحصائية كانت ذات دلالة لصالح المجموعة التجريبية التي درست باستخدام

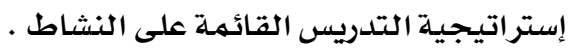

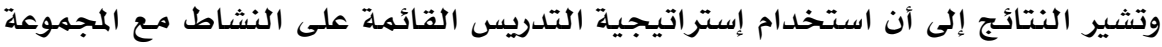

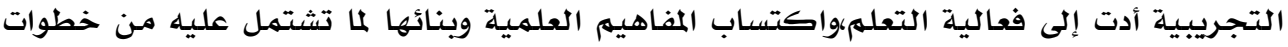

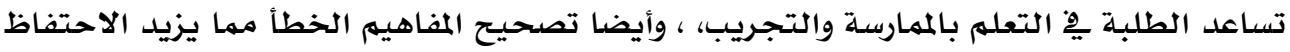

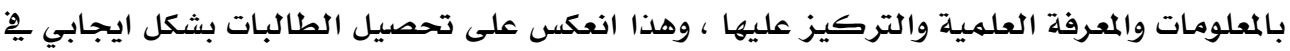

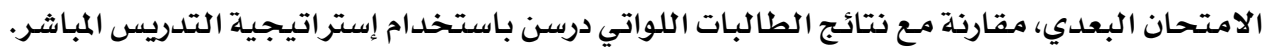




\section{Abstract}

The current study aims at exploring to what extent the scientific concepts in the General Sciences Course(GSC) have been acquired/learned by the $4^{\text {th }}$ grade students of the basic stage in the first semester in Jordan.To this end, the researcher(s) has employed two different teaching strategies: one method of teaching focused on applying various scientific activities, the second based on traditional controlled teaching. The present study is an attempt seeking answer for the following question:

(1)Does the performance of students differ in the appointment test attributed to the implemented teaching strategy?

To accomplish the aims of the study, the teaching material of GSC for the $4^{\text {th }}$ grade has been prepared for the two different strategies, the usual controlled teaching and the one based on scientific activities. Teaching of the prepared material delivered to 76 students from Khawlah Bint ALAzwar school-basic stage, First Directory of Education-Amman.the 76student sample was divided into two groups: the controlled group( 37), and the experimental group (39) .. To answer the question raised by this study, data was collected through conducting two attainment tests: pretest and posttest on the two groups covering three units of environmental and living things, light and substance properties and its forms. The test has 8 various subjective and objective questions with their subquestions. A refereed committee of experts in the field judged and approved the content validity of the test. Data were analyzed through (SPSS).

Pedagogically, findings of the posttest revealed that there is a statistical significant difference in favor of the experimental group supporting the teaching strategy based on scientific activities. By way of conclusion, the study proved that implementing teaching strategies based on scientific activities much better, more effective and fruitful in acquiring the scientific concepts of the GSC than the traditional approach of teaching, and this was reflected in the obtained results in favour of the experimental group compared with the controlled group results. 
ملحق (1)

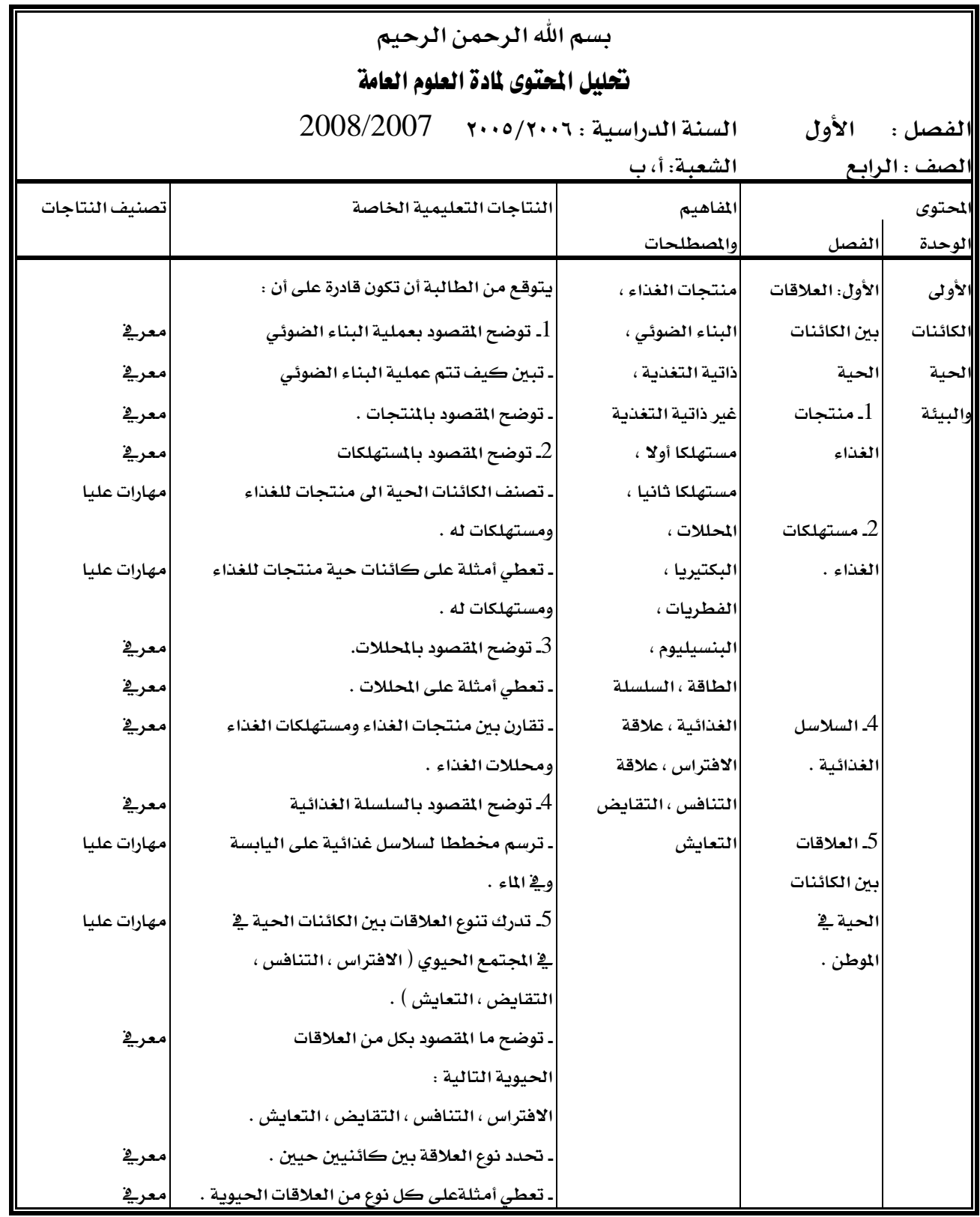




\begin{tabular}{|c|c|c|c|c|}
\hline & النتاجات التعليمية الخاصة & | والمفاهيم & | الفصل & المحتوى \\
\hline 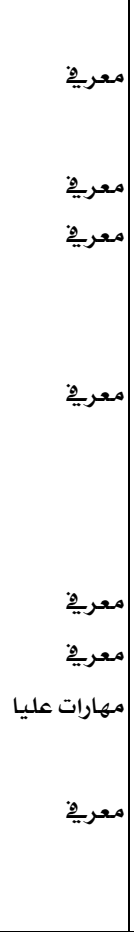 & 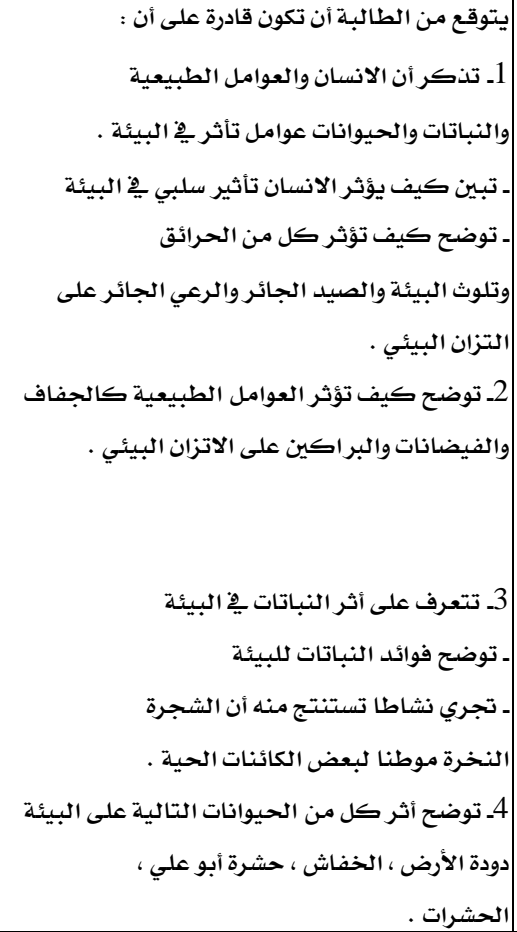 & 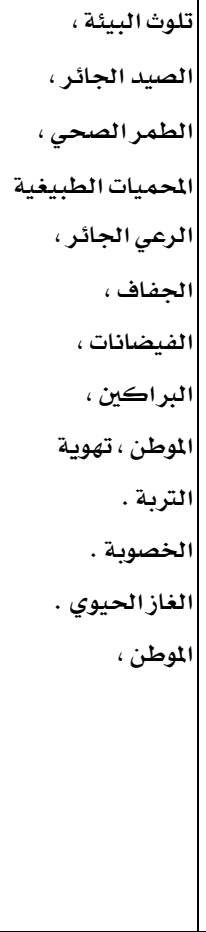 & 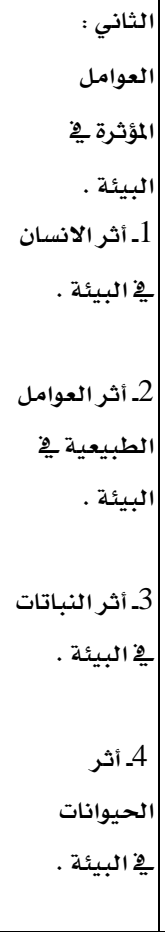 & 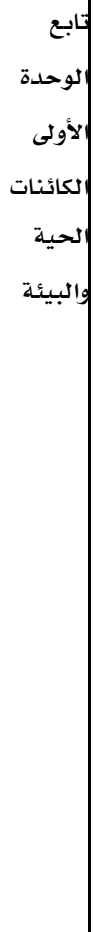 \\
\hline & يمية الخاصة & | والمصاهيم & | الفصل & المحتوى المحدة \\
\hline معريق & 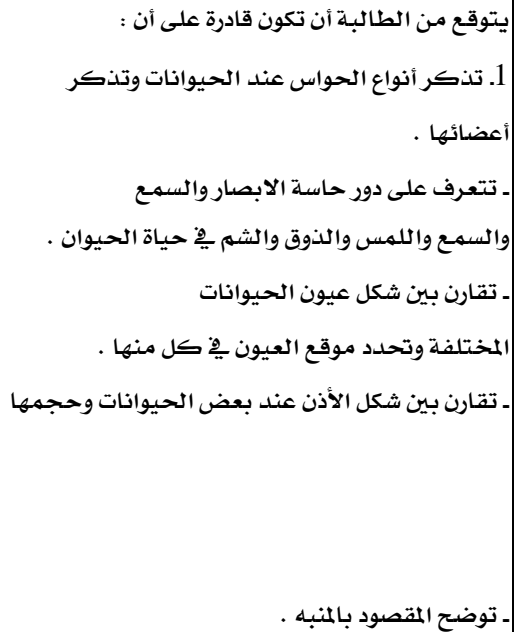 & 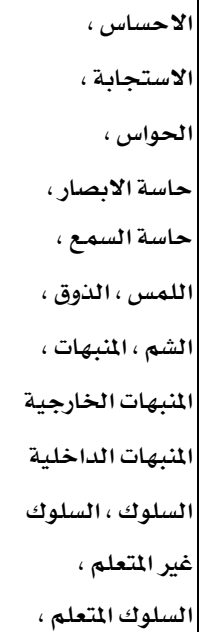 & 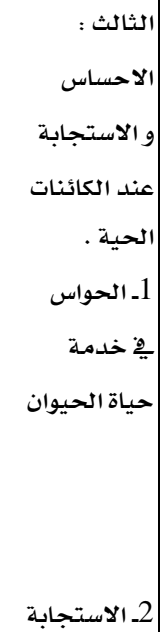 & 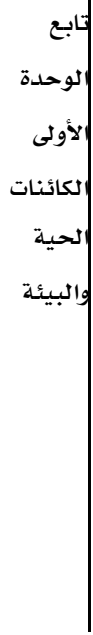 \\
\hline
\end{tabular}




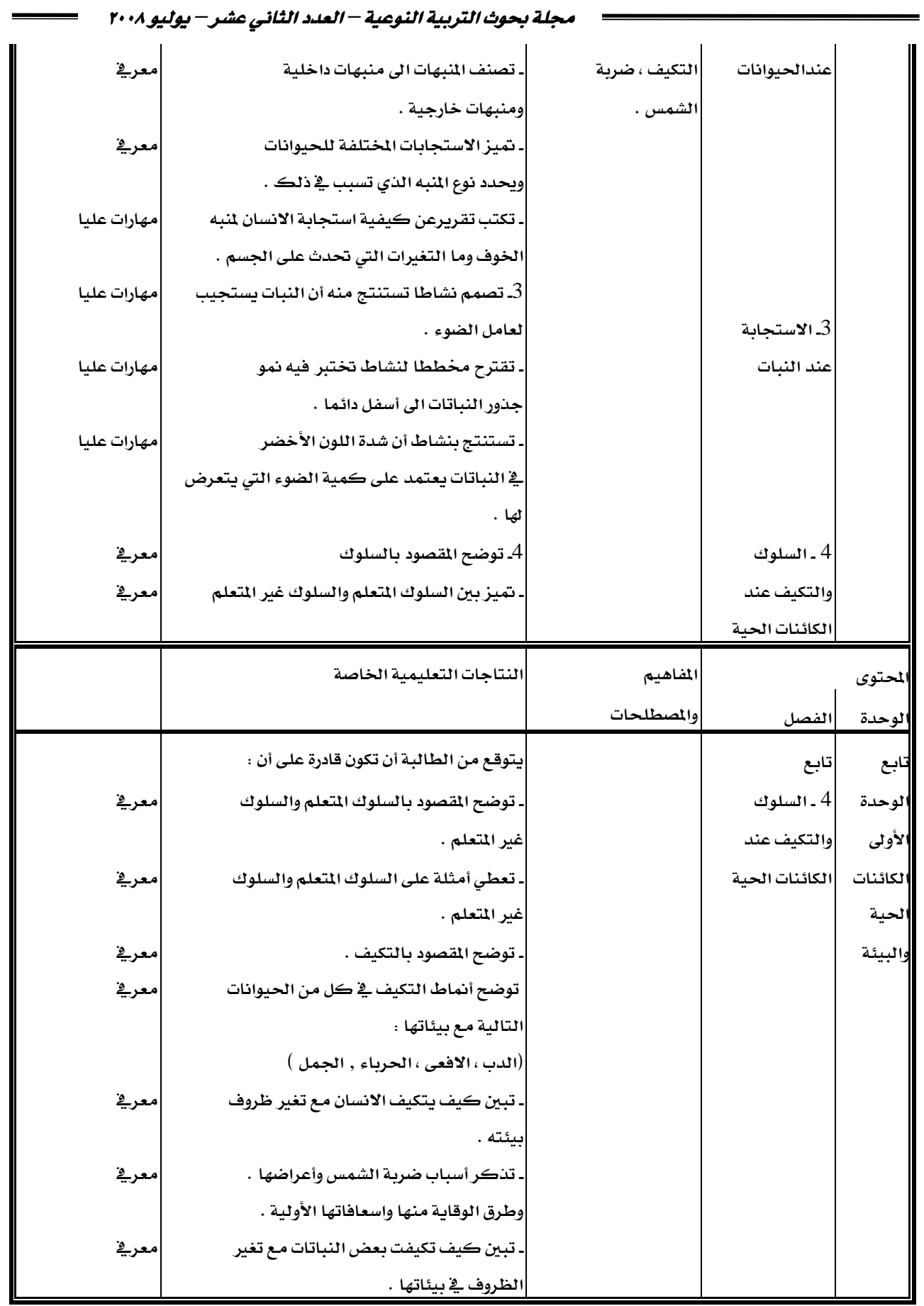


ملى اكتساب المفاهيم العلمية للى طلبة الصف الرابع الأساسي فِ الأردن

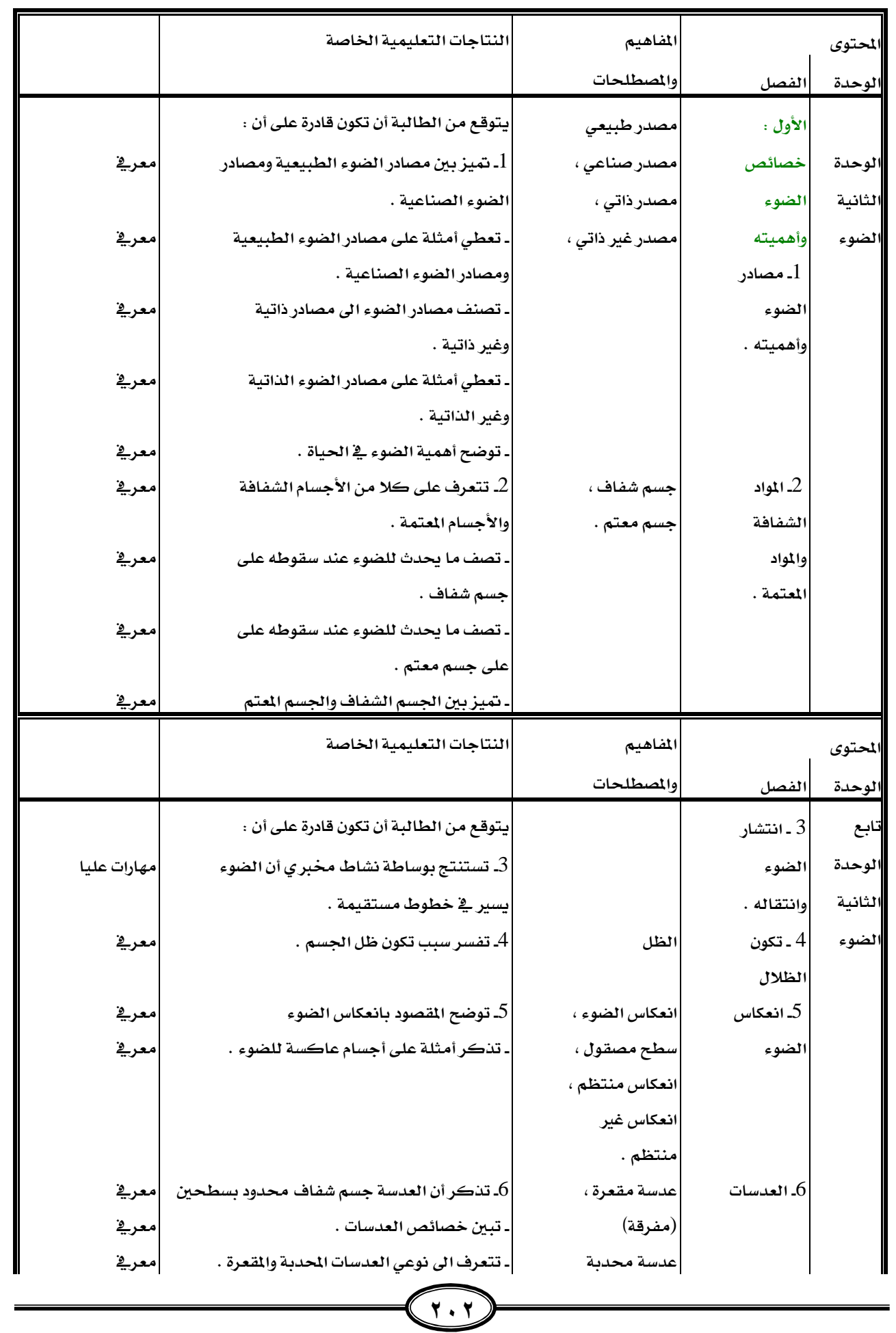




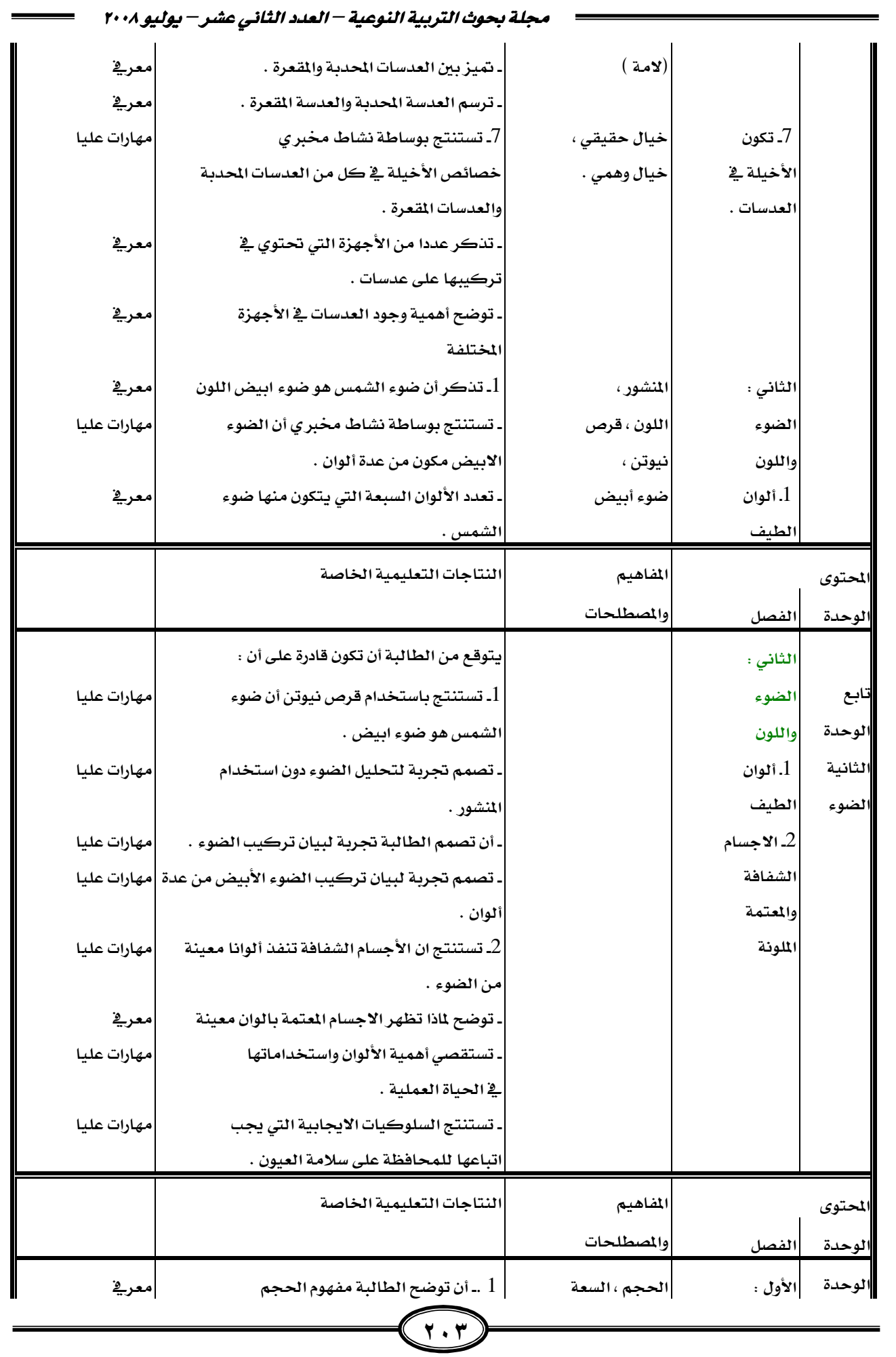




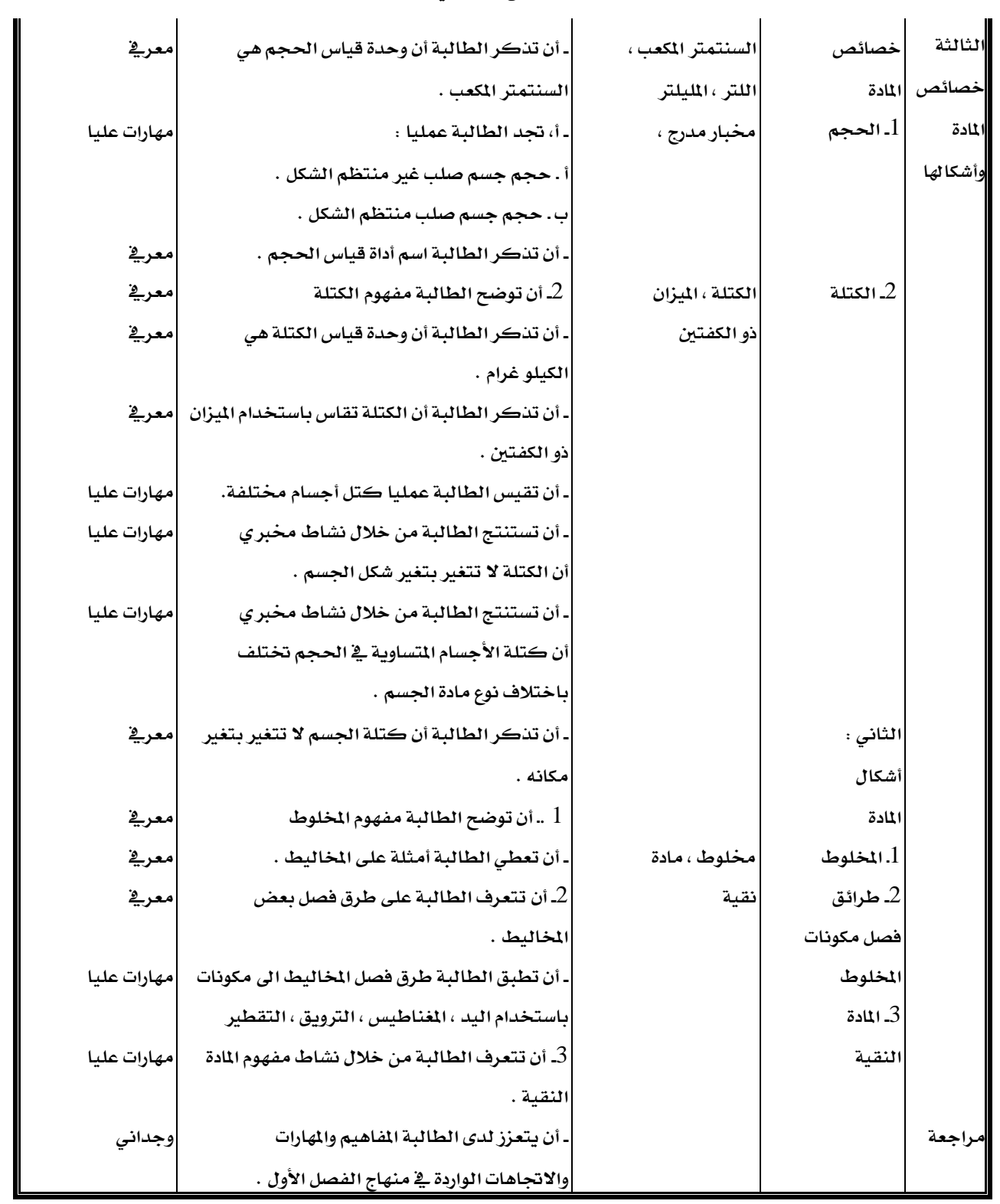




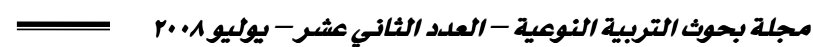

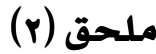

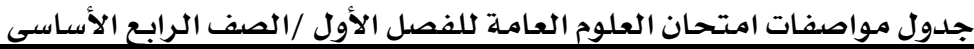

\begin{tabular}{|c|c|c|c|c|c|c|c|c|}
\hline 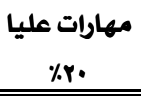 & معرفة •^^٪ & العلامة & متوسط الوزن & |وزن الحص & عدد الحص & وزن الأهداف & الأهداف & الوحدة \\
\hline$\varepsilon$ & IV & $r^{\prime}$ & .01 & $\begin{array}{l}\frac{r q}{01} \\
.0 v=\end{array}$ & rq & $\begin{array}{l}\frac{\varepsilon 7}{9 \varepsilon} \\
. \leqslant q=\end{array}$ & $\sum T$ & $\begin{array}{c}\text { الكائنات الحية } \\
\text { الأولى } \\
\text { البيئة }\end{array}$ \\
\hline r.o & 9 & 11,0 & . YAO & $\begin{array}{l}\frac{11}{01} \\
.10=\end{array}$ & ir & $\begin{array}{l}\underline{r .} \\
q \varepsilon \\
. r Y=\end{array}$ & $r$. & الضانية : \\
\hline 1,0 & 1 & $\mathrm{v}, 0$ & .110 & $\begin{array}{c}9 \\
01 \\
.11=\end{array}$ & 9 & $\begin{array}{l}11 \\
9 \varepsilon \\
.19=\end{array}$ & 11 & خصائص المادة \\
\hline
\end{tabular}

ملحق(r)

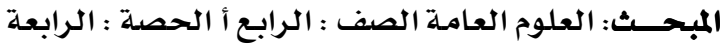

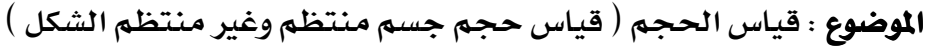

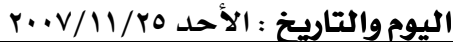

\begin{tabular}{|c|c|c|c|}
\hline مصادر التعلم & |ستراتيجيات التقويم| & استراتيجيات التدريس/خطوات التنفيذ & النتاجات الخاصة \\
\hline \multirow{3}{*}{ 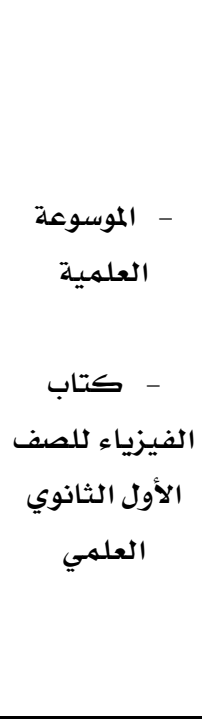 } & \multirow{3}{*}{ 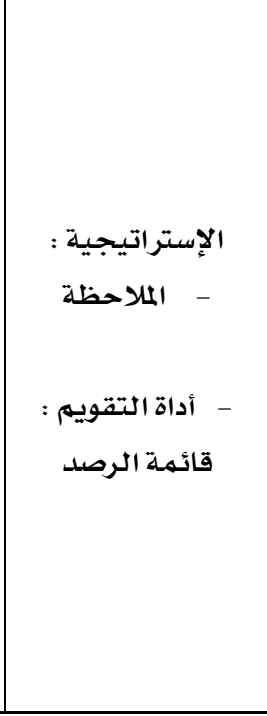 } & 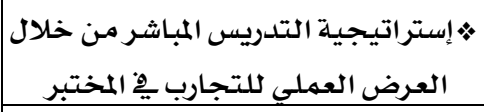 & $\begin{array}{c}\text { يتوقع من الطالبة أن تكون } \\
\text { قادرة على أن }\end{array}$ \\
\hline & & 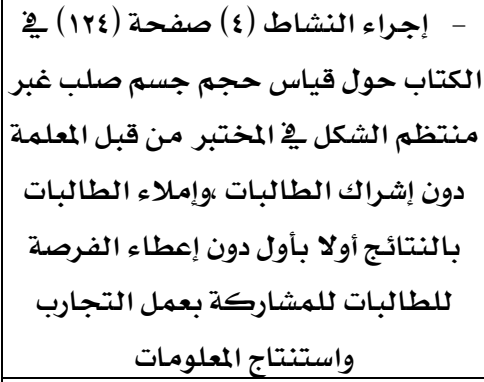 & صلب غير منتظم الشكل جسم جسم \\
\hline & & 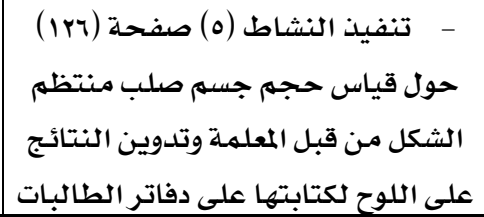 & صلب منتظم الثكل حسم جسم \\
\hline
\end{tabular}

ملاحظات : تم إجراء النشاطين من قبل المعلمـة 


\section{ملحق (0)}

المبحـث : العلوم العامـة الصف : الرابع ب الحصدة : الثانية

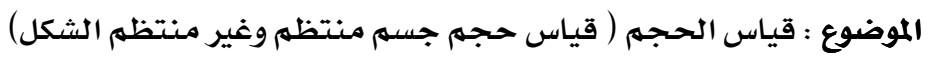

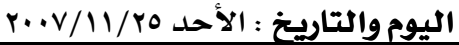

\begin{tabular}{|c|c|c|c|}
\hline مصـادر التعلهم & استراتيجيات التقويم & استراتيجيات التدريس/ ختفيذ & النتاجـات الخاصـة \\
\hline \multirow{3}{*}{ - العلميلة - الفيزياء كلأبل } & \multirow{3}{*}{ الاستراتيجية : الدماة التقلة } & 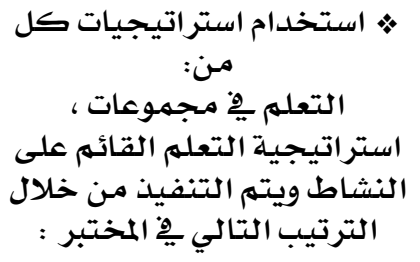 & تيتوقع مـن ادرة على البــ أن \\
\hline & & 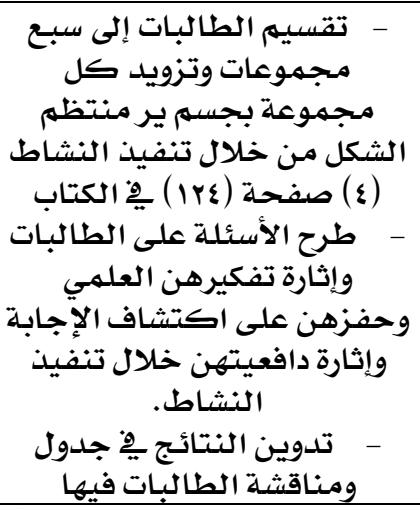 & جسم غير منتظم حجم \\
\hline & & 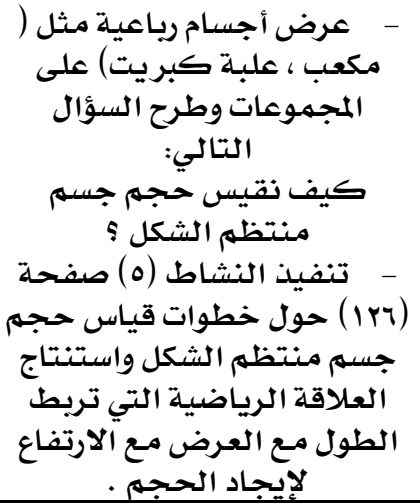 & 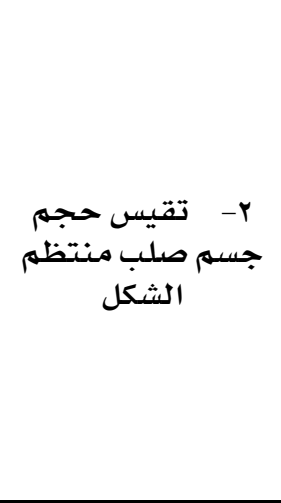 \\
\hline
\end{tabular}




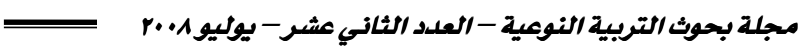

\section{ملحق (0)}

ملاحظات : تم إثراك جميع الطالبات يِّ تنفيذ الأنشطة واستنباط النتائج

\section{ملحق}

مديرية تربية عمان الأولى أسئلة امتحان الفصل الأول الاسم : المدرسة :خولة بنت الأزور لمبحث العلوم التاريخ: .

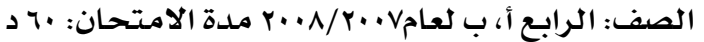

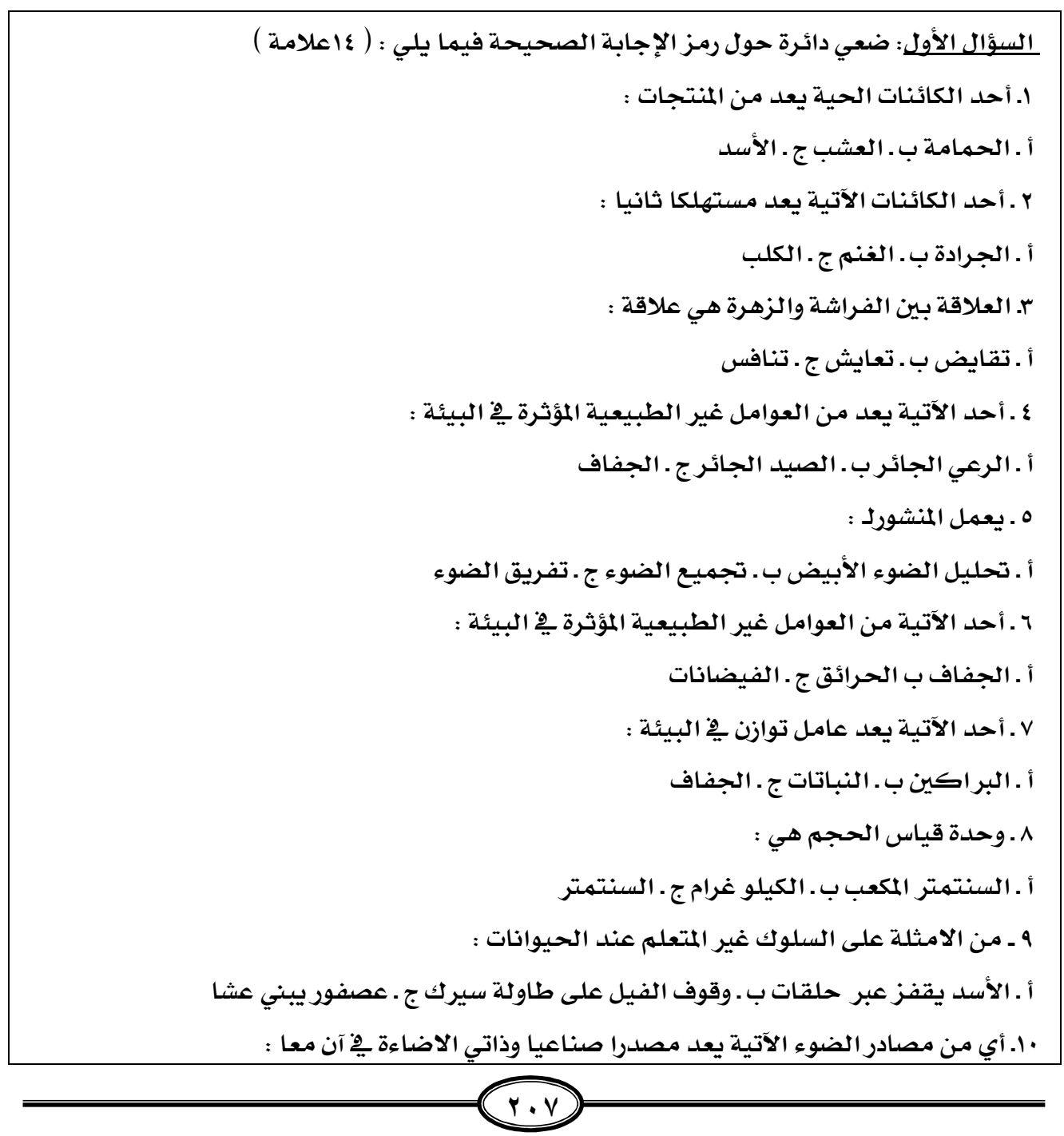




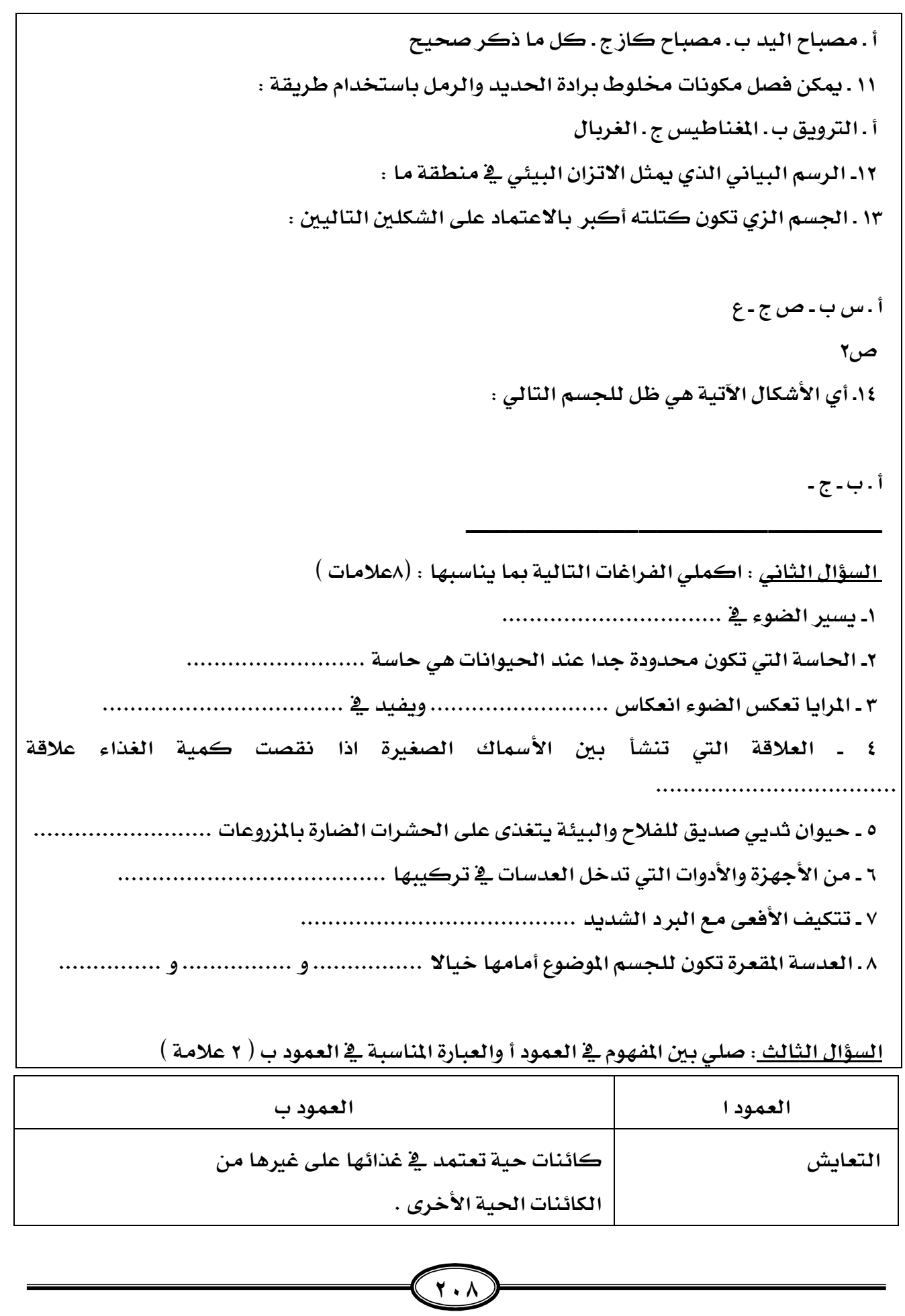




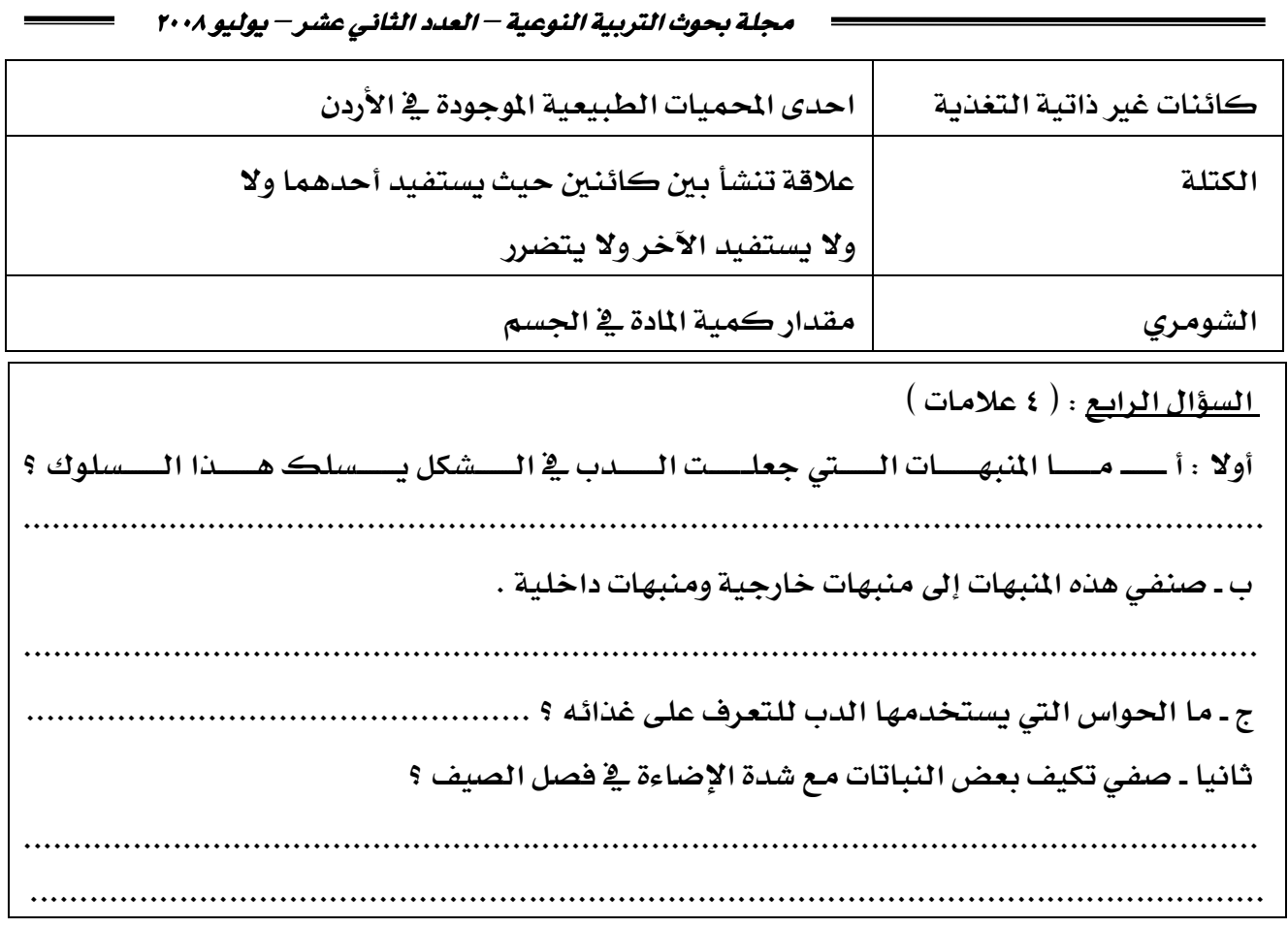

السؤل الخامس : ( ب, ع علامـة )

ـ ـ صنفي المواد التالية الى مجموعتين ، مواد شفافة و مواد معتمهة كما يِ الجدول الذي يليها : قطعة خشب ، لوح زجاجي نقي ، الهواء ، قطعة كرتون ، حجر ، ماء نقي

\begin{tabular}{|c|c|}
\hline مواد معتتمـة & مواد شفافة \\
\hline 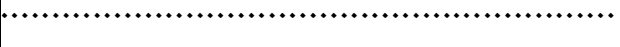 & 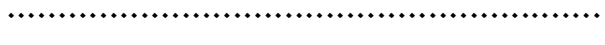 \\
\hline ...... & \\
\hline
\end{tabular}

r ـ صنفي المواد التالية إلى مـادة نقيـة ومخلوط . الحديد ، الهواء الجوي ، مـاء البحر ، أسلاكك نحاس ، الحليب ، مشروب غازي

\begin{tabular}{|c|c|}
\hline مخلوط & مادة نقيـة \\
\hline 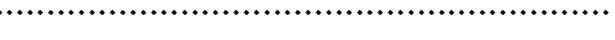 & n...................... \\
\hline 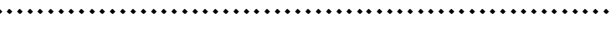 & 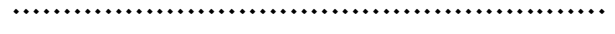 \\
\hline
\end{tabular}

السؤل السادس:اكتبي مثالا واحدا على كل مما يلي : (معلامات ) 1 ـ مصدرا طبيعيا للضوء 


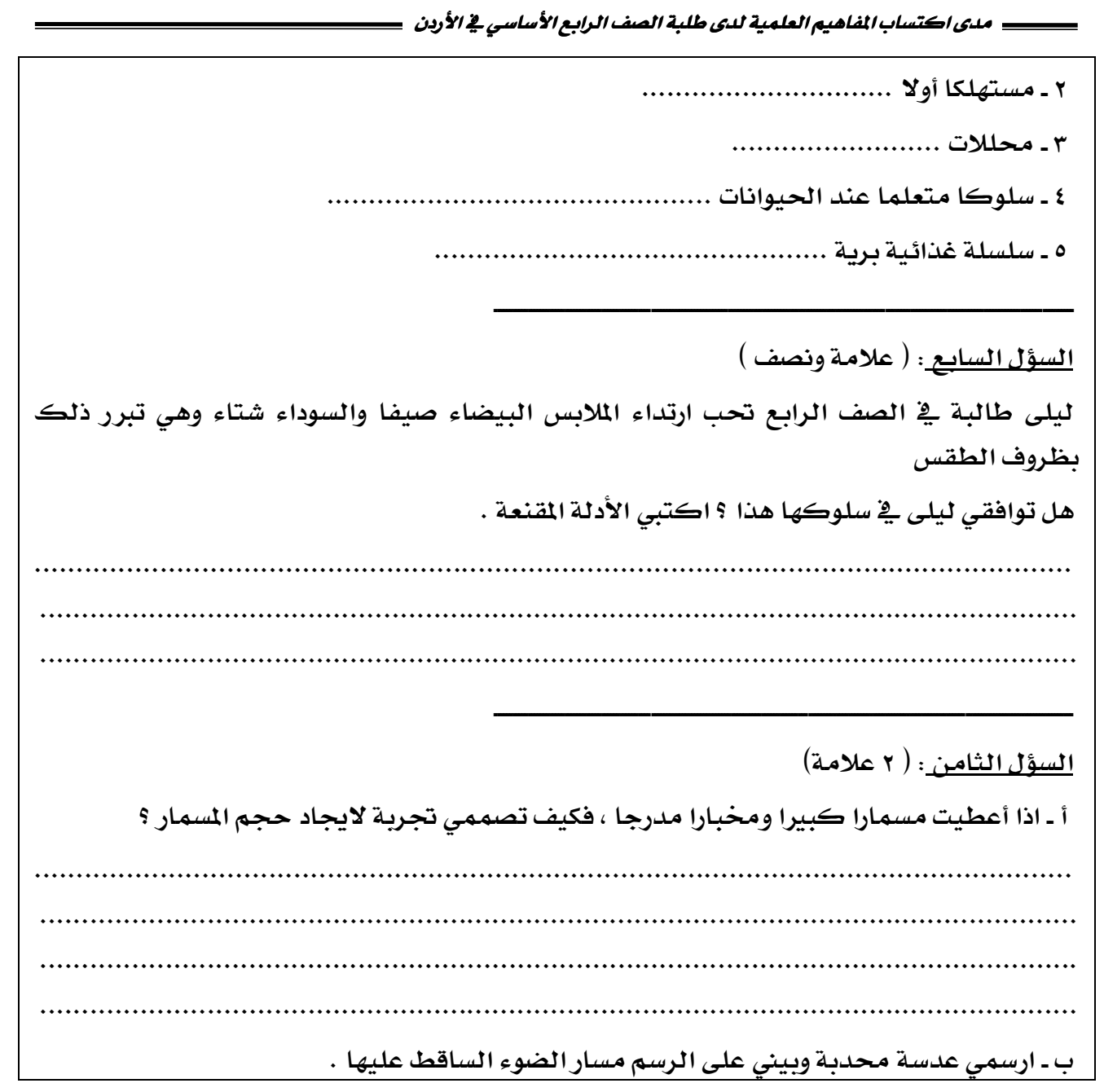

ب ـ ارسمي عدسة مححدبة وبيني على الرسهم مسار الضوء السـاقط عليها .

\footnotetext{
مـع تمنياتي بالنجاح

إعداد: د. سـامرة سعيد طحاينة
} 